\title{
How Chinese and American Students Construct Explanations of Carbon-Transforming Processes
}

\author{
Pingping Zhao ${ }^{1^{*}}$, Charles W. Anderson ${ }^{2}$, Emily Scott ${ }^{3}$, Karen Draney ${ }^{4}$, JinHo Kim ${ }^{4}$ \\ ${ }^{1}$ College of Life Science, Hebei Normal University, Shijiazhuang 050024, CHINA \\ ${ }^{2}$ College of Education, Michigan State University, East Lansing, MI, USA \\ ${ }^{3}$ Department of Biology, University of Washington, Seattle, WA, USA \\ ${ }^{4}$ Graduate School of Education, University of California, Berkeley, CA, USA
}

Received 7 May 2018 - Revised 24 October 2018 - Accepted 13 December 2018

\begin{abstract}
Previous studies reported a learning progression that described the development of American students' explanations of carbon-transforming processes. This study examined the validity of this learning progression for Chinese middle school students. The comparison of American and Chinese students' performances showed both similarities and differences between the two groups. They shared similar general trends in their learning progressions from simple force-dynamic accounts to scientific modelbased reasoning. Most students did not construct model-based explanations: (1) they did not trace matter and energy separately, and (2) they did not connect phenomena at the macroscopic scale to mechanisms at the cellular and atomic-molecular scale. There were some key differences. These differences might be due to culture, exam systems, or other aspects of science education in these two countries. Implications for improving science education in each country are discussed.
\end{abstract}

Keywords: carbon cycling learning progression, carbon-transforming processes, crosscutting concepts, model-based explanations, three-dimensional learning

\section{INTRODUCTION}

This article reports on our work in exploring how Chinese middle school students construct model-based explanations of carbon-transforming processes and comparing Chinese and American students' performances. Currently, there is limited understanding of how Chinese middle school students understand carbon cycling. We conducted a search in the Education Resources Information Center (ERIC) and China National Knowledge Internet (CNKI) using 'carbon cycling' and 'secondary education in China' as keywords in titles and found few results. We use a carbon cycling learning progression framework to describe the development of students' explanations of carbon-transforming processes.

\section{Model-based Explanations of Carbon-transforming Processes}

With the release of the Next Generation Science Standards (NGSS) in the United States, science teachers, curriculum developers and researchers are working on integrating practices, core ideas, and crosscutting concepts into science classrooms for students. In this study, we focus on the practice of constructing explanations because it is an important measure of students' understanding of scientific concepts and a central aspect of science education (NGSS Lead States, 2013; NRC, 2012).

Previous studies refer to scientific explanations generated from constructed models as model-based explanations, which is a powerful sense-making practice (Zangori et al., 2015). Models are idealized structures that we use to represent the world, via resemblance relations between the model and real-world target systems (Giere, 1988). A critical purpose of a scientific model is to help explain natural phenomena (Justi et al., 2002a; Zangori et

(c) 2019 by the authors; licensee Modestum Ltd., UK. This article is an open access article distributed under the terms and conditions of the Creative Commons Attribution License (http://creativecommons.org/licenses/by/4.0/).

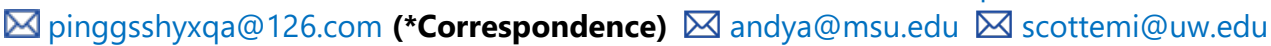




\section{Contribution of this paper to the literature}

- Provides evidence that the American carbon cycling learning progression framework and American assessments could be used in China, implying that learning progression (LP) frameworks and assessments developed in one country could be used in the other.

- Gives us deeper insight into the similarities and main problems that American and Chinese students both have when explaining carbon-transforming processes, suggesting the Carbon TIME curriculum could help Chinese students achieve environmental science literacy.

- Presents the key differences between American and Chinese students' explanations of carbon-transforming processes.

al., 2015). Students can use models as sense-making tools to help them understand the underlying scientific theory for phenomena and generate scientific explanations (Zangori et al., 2015).

When students consider both visible and non-visible components in a system, they can use models as explanatory tools to identify the underlying cause and effects in the system and to generate model-based explanations connecting what happened with how and why it occurred (Gilbert, 2004). When students develop models of their ideas about the phenomena and use their models to articulate model-based explanations, their thinking becomes visible and their understanding about the phenomena deepens.

In this study, we focus on students' explanations of carbon-transforming processes. Carbon-transforming processes include organic carbon generation, transformation and oxidation (Jin, Zhan, \& Anderson, 2013). Organic carbon generation refers to the process that generates organic carbon compounds from inorganic substances (carbon dioxide, water, etc.). Photosynthesis is the only process that generates organic carbon compounds. Organic carbon transformation refers to the processes of passing on chemical energy within ecosystems and from ecosystems to human socio-economical systems. For example, a child needs materials from other organisms within ecosystems to live and grow. Digestion and biosynthesis are processes that transform organic carbon. Organic carbon oxidation refers to the processes of releasing energy through oxidizing the organic carbon compounds. Cellular respiration and combustion fulfill this role.

Understanding carbon-transforming processes is central to scientific literacy because explanations of carbontransforming processes are examples of applying specific ways of scientific reasoning to real-life situations (Jin, Zhan, \& Anderson, 2013). Atomic-molecular models of carbon-transforming processes (photosynthesis, digestion, biosynthesis, cellular respiration and combustion) are used to explain macroscopic phenomena (plant growth and movement, animal growth and movement, decay, burning, etc.). Therefore, constructing explanations of carbon transforming processes helps students apply scientific reasoning to solve problems in their daily life and improve their scientific literacy.

To construct scientific explanations of carbon-transforming processes students must also understand and apply crosscutting concepts (NRC 2012). In our work, we pay particular attention to three crosscutting concepts: (1) Energy and Matter: Flows, Cycles and Conservation, (2) Systems and System Models, and (3) Scale, Proportion, and Quantity. These crosscutting concepts are necessary to create thorough explanations, including (1) connecting systems at different scales, and (2) tracing matter and energy. When students connect systems at different scales, they construct explanations that describe carbon-transforming processes at large, macroscopic, cellular, and atomicmolecular scales that provide a more complete story of how a phenomenon happened. When students trace matter and energy, it means they employ the principles of matter and energy conservation as rules to interpret familiar and unfamiliar natural phenomena, and apply these principles consistently across contexts.

However, prior research shows that American students struggle with using the two crosscutting concepts above to construct a thorough explanation. For example, regarding connecting systems at different scales, although students learn about cellular work that supports organism function and study ecosystem structures and functions, they still struggle to develop descriptions for materials and functions at a cellular level and explanations for carbontransforming processes at multiple scales, especially at the middle school level (Mohan, Chen, \& Anderson, 2009). Also, regarding tracing matter and energy, research shows that students often describe the matter cycle as atoms or molecules moving without changing forms, and they describe energy flow as an energy cycle without degradation (Lin \& Hu, 2003). In addition, curriculum materials used in secondary schools often address reactants and products of carbon-transforming processes without articulating the big ideas of how matter and energy are transformed (Stern \& Ahlgren, 2002). Therefore, learning how to construct explanations of carbon-transforming processes is both useful for students and an important issue for educators to explore. 
Table 1. Learning Progression Achievement Levels

\begin{tabular}{ll}
\hline Levels & Characteristics \\
\hline $\begin{array}{l}\text { Level 4: Coherent Scientific } \\
\text { Reasoning }\end{array}$ & $\begin{array}{l}\text { Students successfully apply fundamental principles, such as conservation of matter and energy, } \\
\text { to phenomena at multiple scales and construct scientific model-based explanations. }\end{array}$ \\
\hline $\begin{array}{l}\text { Level 3: Incomplete Scientific } \\
\text { Reasoning }\end{array}$ & $\begin{array}{l}\text { Students show awareness of important scientific principles and of models at smaller and larger } \\
\text { scales, but they have difficulty connecting accounts at different scales and applying principles } \\
\text { consistently and often interconvert matter and energy to account for matter movement and } \\
\text { energy change. }\end{array}$ \\
\hline $\begin{array}{l}\text { Level 2: Elaborated Force- } \\
\text { Dynamic Reasoning }\end{array}$ & $\begin{array}{l}\text { Students' accounts continue to focus on actors, enablers, and natural tendencies of inanimate } \\
\text { materials, but they add detail and complexity at larger and smaller scales, and begin to trace } \\
\text { materials and energy forms that are visible. }\end{array}$ \\
\hline $\begin{array}{l}\text { Level 1: Simple Force-Dynamic } \\
\text { Reasoning }\end{array}$ & $\begin{array}{l}\text { Students' accounts focus on actors, enablers, and natural tendencies of inanimate materials in } \\
\text { the phenomena at a macroscopic scale, without recognizing the underlying matter movement } \\
\text { and chemical change. }\end{array}$ \\
\hline
\end{tabular}

\section{Carbon Cycling Learning Progression Framework}

Learning is an ongoing developmental process. Using a learning progression approach facilitates tracing the development of students' explanations as they increase in sophistication with experience. Previous work investigating students' ideas about carbon cycling has led to a learning progression that focuses on carbontransforming processes that were developed based on data from American elementary, middle, high school, and college students that participated in the Carbon TIME project (Jin \& Anderson, 2012; Mohan, Chen, \& Anderson, 2009).

The carbon cycle learning progression framework contains three important dimensions: Processes, progress variables and levels of achievement.

1. The learning progression is organized around key processes that tie systems together: the generation of organic carbon (photosynthesis), the transformation of organic carbon (digestion, biosynthesis,), and the oxidation of organic carbon (cellular respiration, combustion) (Mohan et al., 2009).

2. Progress variables include four key elements of scientific explanations in the learning progression: contextspecific knowledge, orientation towards principles of matter and energy, precision in matter and energy words, and scale. "Context-specific knowledge" refers to factual components of the disciplinary core ideas. "Orientation towards principles of matter and energy" refers to how students use the crosscutting concept of Matter and Energy Conservation as principles or rules that can be applied across contexts. "Precision in matter and energy words" identifies how clearly students distinguish matter and energy words. "Scale" identifies how students connect the large scale, macroscopic scale, cellular scale, and atomic-molecular scale (Miller, Johnson, Freed, Doherty, \& Anderson, 2017).

3. Previous studies (Jin et al., 2012; Mohan et al., 2009) about the carbon cycle learning progression framework have identified four levels of achievement that describe students' progress toward more sophisticated reasoning about matter and energy within these processes.

The framework includes a Lower Anchor (level 1) that describes what students know and can do at upper elementary level, an Upper Anchor (level 4) that describes what science educators would hope students would know and do by the end of high school, and two transitional levels (levels 2 and 3 ) that describe intermediate levels of reasoning about carbon-transforming processes between the two anchor points (Mohan et al., 2009). The four learning progression levels are shown in Table 1.

\section{Research Questions}

In this article, we characterize the ways Chinese students construct explanations of macroscopic carbontransforming phenomena (growth of plants and animals, movement and functioning of organisms, decay, combustion) that are linked to atomic-molecular processes that generate, transform, and oxidize organic carbon (photosynthesis, digestion \& biosynthesis, cellular respiration and combustion) and compare their explanatory approaches to those of American students. Our work was guided by the following research questions:

(1) How well do the American learning progression framework and American assessments describe and measure the proficiency of Chinese students?

(2) What are the differences among Chinese students in grades 7, 8 and 9 in their explanations of carbontransforming processes?

(3) What are the similarities and differences between American and Chinese students in their explanations? 
Table 2. The Number of Chinese Students at Each Grade Level

\begin{tabular}{ccc}
\hline Grade Level & No. of Chinese Students at Each Grade & Total \\
\hline Seventh & 76 & 337 \\
Eighth & 137 & \\
Ninth & 124 & \\
\hline
\end{tabular}

\section{METHODS}

\section{Participants}

In this study, we collected written responses to assessment instruments from 337 students (7th, 8th and 9th grades) from one public school in Sichuan, a southwest province in China, in November, 2015. The sample school is one of urban schools in Chengdu, the provincial capital of Sichuan, and provides ordinary educational resources to students. The students who attended the school could be described as belonging to urban and suburban areas, with the school serving families of low, middle, and upper income. Table 2 lists the number of Chinese students at each grade level.

We compared the Chinese student written responses to the responses of American middle school students' who participated in the Carbon TIME project during the 2015-16 school year. American teachers administered the 201516 Carbon TIME Assessments to their students as baseline-tests (at the end of the school year before the teachers participated in the Carbon TIME program: 2,287 students), pre-tests (at the beginning of the school year the teachers participated in Carbon TIME: 3,200 students), and post-tests (at the end of Carbon TIME instruction: 2,106 students). In addition, we interviewed 12 Chinese middle school students from Beijing and Guangzhou province and compared their responses with those of 50 American middle and high school students from Carbon TIME (Miller, Johnson, Freed, Doherty, \& Anderson, 2017).

Our data collection process was based on a convenience sample and only provides a glimpse of how Chinese and American students construct model-based explanations of carbon-transforming processes. Therefore, the conclusions we draw may not be applicable to all Chinese and American students.

\section{Instruments}

The written assessments and interview protocol in the Carbon TIME project were translated into Chinese by the first author and used to collect data from Chinese students. In order to make sure the translation was accurate and easy for Chinese students to understand, two additional researchers from the Carbon TIME project reviewed the translations: one was a native Chinese speaker, the other was a native English speaker but worked in China for several years and was proficient in Chinese. We made changes to the translations based on their comments. After confirming the tests and interview protocol were completely understandable, they were administered to Chinese students.

Written assessments were designed to assess students' learning progression of carbon cycling, and included three alternate forms: Form A had 13 assessment items, Form B had 12 assessment items, Form C had 12 assessment items. Some items acted as linking anchor items and appeared on more than one form. Most items had two parts; a multiple choice or multiple True or False part, followed by a constructed response part that required students to explain their choice. Three types of items were included in each form: Carbon LP (Learning Progression) items, Inquiry LP items and Large-scale-LP items. The IRT analyses for Carbon LP items in 2015-16 datasets were more reliable, Carbon LP items were chosen to compare how American and Chinese students explain carbontransforming processes. The interview protocol (see Appendix A) was an expanded version of written tests and included a total of seven tasks designed to elicit more thorough student reasoning about carbon-transforming processes.

\section{Scoring Process}

Chinese students' responses to the written assessments were scored using scoring rubrics that correspond to the response characteristics described at each of the four learning progression levels in the Carbon TIME project. One example of scoring rubrics can be found in the Appendix B. Students' written responses were coded into levels 2 through 4 . (Test items were not designed to elicit Level 1 responses, which are most common in elementary students' performances instead of middle school students'.) $10 \%$ of the responses were randomly selected to be translated into English by the first author, then were double scored by a second rater to examine the scoring quality and reduce scoring errors. If there was less than $90 \%$ agreement of assigned codes for this $10 \%$ of responses, the 
raters met to discuss any issues with the scoring rubrics or their interpretation and re-score responses to that item. An inter-rater reliability between the first and second rater of $>90 \%$ was achieved for all items.

The first and second raters coded students' responses based on the indicators for each learning progression level in the scoring rubric. Chinese responses were classified according to whether they fit into the indicators in the American scoring rubric. We found some disconnect between Chinese students' responses and the American scoring rubric. For example, some of the Chinese students mentioned photosynthesis or the reaction between the leaves and oxygen as the cause of heat generation, which did not appear in American students' responses. To account for this discrepancy, we assigned level 3 for "photosynthesis" responses and level 2 for "the reaction between the leaves and oxygen", and considered these Chinese responses to be "different".

Most of American students' written responses were coded by computer. It is expensive and time consuming to score composite items that include both forced choice (FC) and constructed response (CR) components requiring human coders to read and score each CR component. Therefore machine learning was used for automated scoring of student responses (Thomas, Kim, \& Draney, 2018). ML engine (LightSide Researcher's Workbench) was used to extract information at the SUBLEVEL category and able to notice patterns in FC responses that were not part of the human scoring rubric. A model was considered acceptable if it produced a quadratic weighted kappa (QWK) greater than 0.7 with the training set (Fleiss \& Cohen, 1973). If an acceptable model could not be built, then problematic answers were back checked by an expert human coder to determine if the error was of human or computer origin. Once the revised human codes replaced the problematic codes, the model was rebuilt and tested (Thomas, Kim and Draney, 2018). For the 15-16 data, 30 of 31 models had at least marginal QWK of 0.6 or greater when backcoded by human scorers with a stratified random sample.

All Chinese students' interviews were translated into English and coded using a framework developed in a previous American study (Miller, Johnson, Freed, Doherty, \& Anderson, 2017) that identified four progress variables mentioned above. Because the main purpose of analyzing the interviews was to characterize the similar and different ways American and Chinese students reasoned in the interviews, we did not calculate inter-rater reliability for this analysis.

\section{Data Analysis}

In order to address the three research questions, qualitative and quantitative analyses were carried out. Qualitative analyses were used to summarize the general patterns in responses to written assessments and interviews from American and Chinese students. Quantitative analyses, including descriptive statistics and Item Response Theory (IRT) analyses, were used to provide the mean percentage of students' constructed responses at each grade, and compare estimates of students' overall proficiency, etc. We conducted three sets of IRT analyses. First, we fitted the unidimensional Partial Credit Model (PCM; Masters, 1982) to the ordinally scored students' responses which had learning progression levels. In the PCM, the conditional probability that person $p$ with ability $\theta_{p}$ would respond with category score $m$ on item $i$ with step difficulty parameters $\delta_{i m}$ is defined as:

$$
\operatorname{Pr}\left(y_{p i}=m \mid \theta_{p}\right)=\frac{\exp \left(\sum_{l=0}^{m}\left(\theta_{p}-\delta_{i l}\right)\right)}{\sum_{h=0}^{M_{i}} \exp \left(\sum_{l=0}^{h}\left(\theta_{p}-\delta_{i l}\right)\right)}, m=0,1, \ldots, M_{i},
$$

where $\theta_{p} \sim N\left(0, \sigma_{\theta}^{2}\right), \delta_{i 0}=0$, and $\sum_{l=0}^{0}\left(\theta_{p}-\delta_{i l}\right)=0$. This IRT model produced estimates of step difficulties between levels of an item, proficiency estimates for students, and fit statistics for individual items and persons (students). A Wright map, item fit plot, and person fit histogram were generated to present these results, which can enable us to obtain validity evidence based on the internal structure of the Carbon assessments. Second, the unidimensional latent regression IRT model based on the PCM was fitted to the Chinese data to examine differences in overall Chinese students' proficiency between the three grades. Third, we conducted a differential item functioning (DIF) IRT analysis on the merged American and Chinese data to compare individual item performance between the two countries. DIF is a good way to analyze how Chinese and American students respond differently to individual items. This analysis puts the overall average proficiency of both American and Chinese students at 0 , then compares item difficulties, so negative DIF parameters for American students mean that the item was easier for American ones, and negative DIF parameters for Chinese students mean that the item was easier for Chinese ones.

The ConQuest software (Wu, Adams, Wilson, \& Haldane, 2007) was used for all IRT analyses, and the R package 'WrightMap' was used to draw Wright maps and item fit plots (Irribarra \& Freund, 2014). 


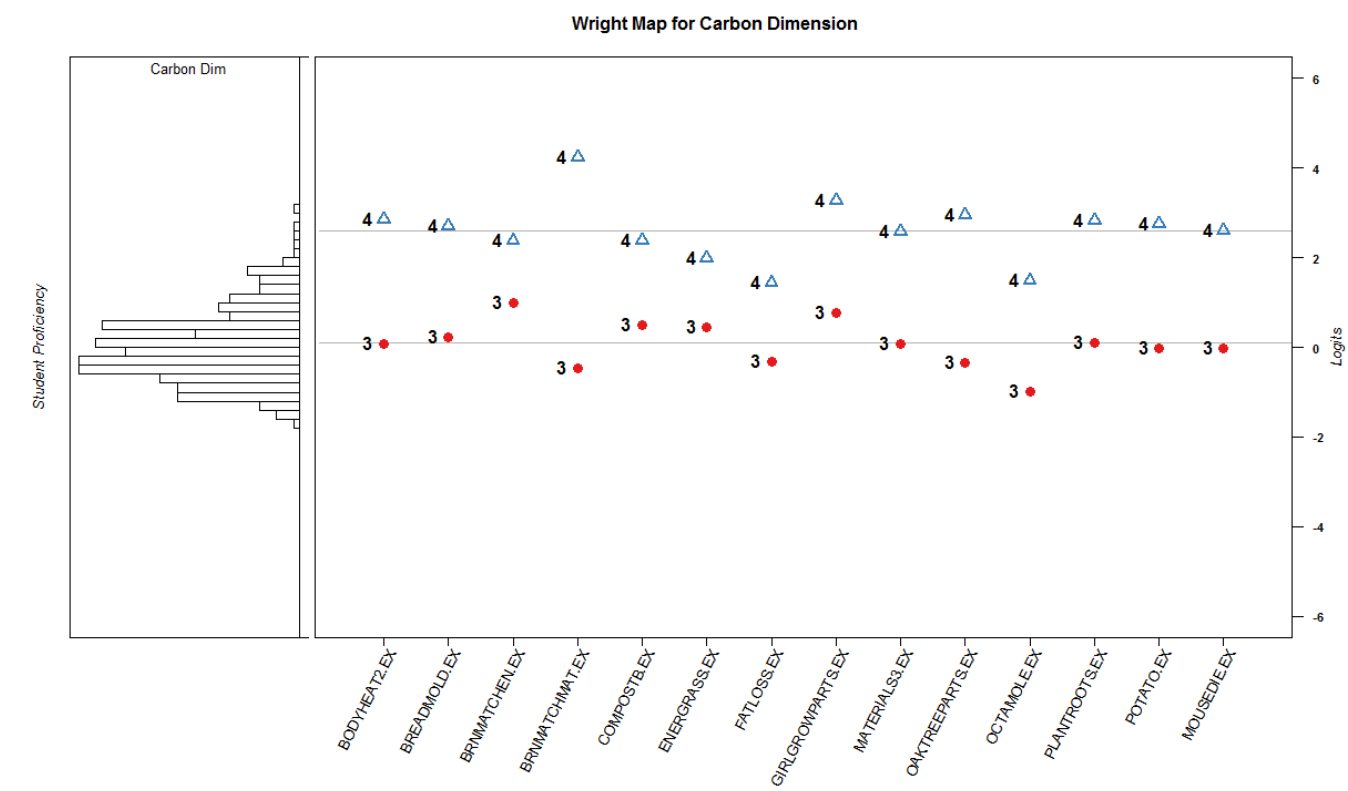

Figure 1. The Wright Map for Chinese students on Carbon LP Items

\section{RESULTS}

\section{Research Question 1: The Validity of American Assessments and American Carbon Cycle Learning Progression Framework for Chinese Students}

We provide three kinds of evidence to verify whether or not the American assessments and carbon cycle learning progression framework work for Chinese students: IRT analysis, comparisons of American and Chinese students' constructed responses, and patterns in students' interviews.

\section{Evidence from IRT analysis}

In Figures 1 and 2, the round and triangle dots are the thresholds, which are indicators of "score difficulties". The threshold for a score category is defined as the ability at which the probability of achieving that score or higher reaches $50 \%$. The round dots represent the difficulty for achieving a score of 3 and above, or the thresholds from level 2 to 3 . The triangle dots represent the difficulty for achieving a score of 4 and above, or the thresholds from level 3 to 4 .

Based on our IRT analyses, we found that the patterns of learning progression levels were generally similar between the American and Chinese students (Figures 1 and 2). Most of the thresholds from level 2 to 3 were in the same logit range, and well separated from the thresholds from level 3 to 4 , suggesting the carbon cycle learning progression framework from the Carbon TIME project is valid to classify the responses from the Chinese student sample and measure Chinese student reasoning of carbon-cycling items. Only a few items had thresholds that were not well differentiated for both level 2 to 3 and level 3 to 4 . 


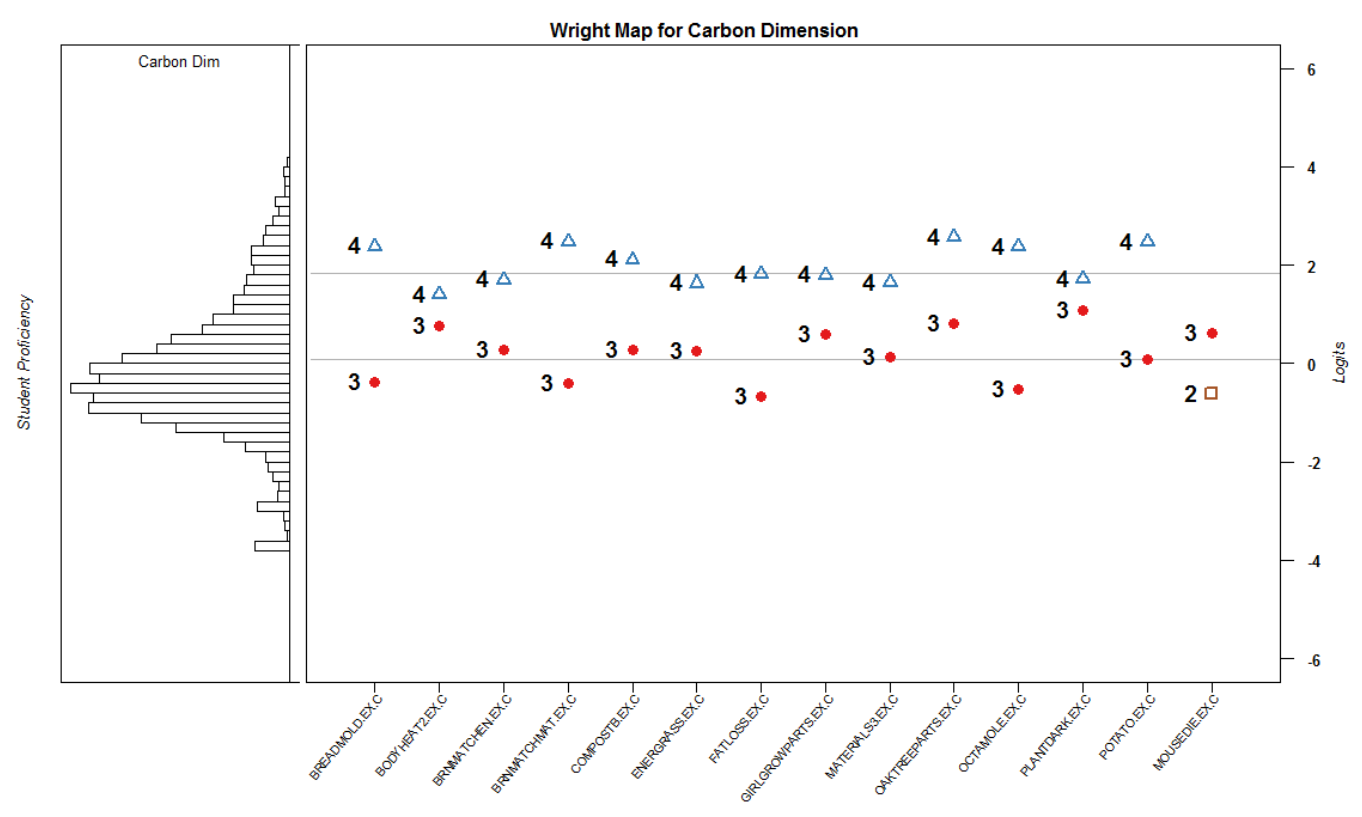

Figure 2. The Wright Map for American Students on Carbon LP Items

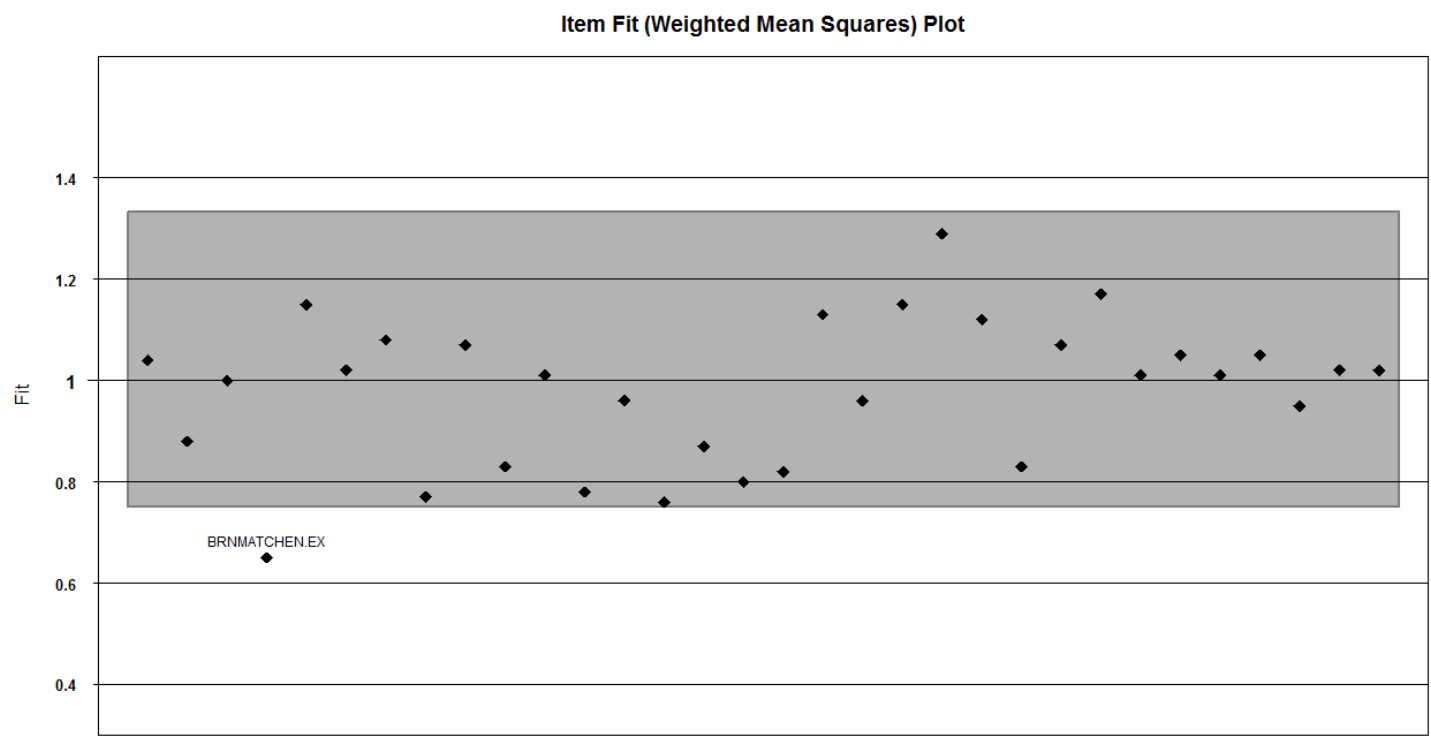

Figure 3. The Item Fit Plot for Carbon LP Items

Item fit statistics (Figure 3) provide information about how well the data for an individual item fit the IRT statistical model. Each dot represents a fit statistic for one item. Items that have low fit statistics show less random variation than expected, and are usually not a concern. However, items that have high fit statistics show more random variation than expected. This means that a large number of high-performing students who are doing worse than expected, and/or a large number of low-performing students who are doing better than expected. Therefore, item fit statistics provide evidence to examine internal structure validity. The results showed that the Mean-Square statistics (MNSQs) of all the items were within the acceptable range (0.6-1.4) (Wright, Linacre, Gustafsson, \& Martin-Loff, 1994), suggesting such items have acceptable fit and can be used for pretest and posttest analysis in an assessment.

Low student fit statistics indicate sets of responses that are very regular, and high student fit statistics indicate more random variation than expected. Students with fit statistics below the left blue line (the lower bound of the acceptable range) show very regular responses. A large proportion $(40.36 \%)$ of students falls in this range (Figure 4 ), which is additional evidence of the consistency of student reasoning across a wide variety of contexts. 


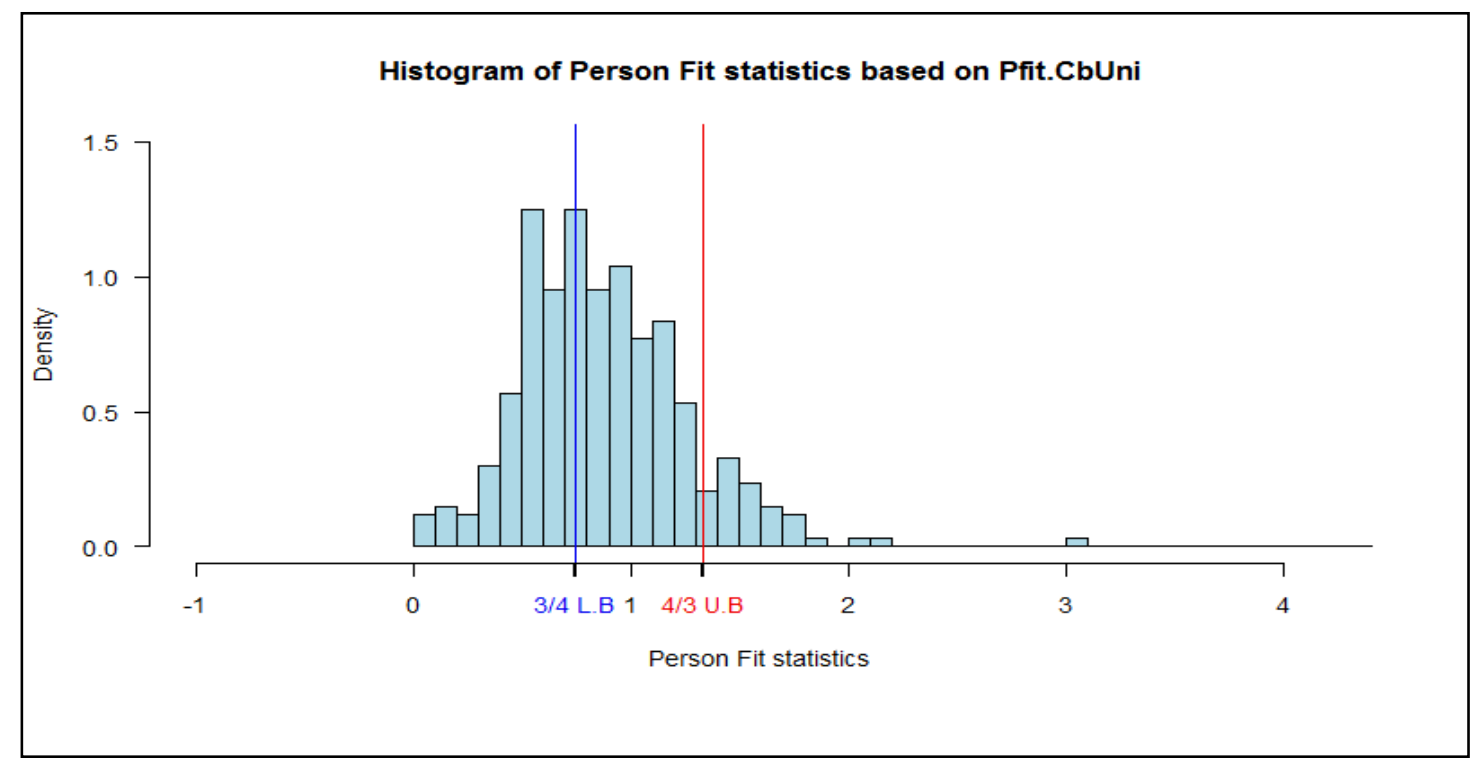

Figure 4. The Overall Student Fit Statistics

Table 3. Summary of the Patterns in Responses from American and Chinese Students for the Carbon TIME Tests

\begin{tabular}{|c|c|c|c|c|}
\hline Students & $\begin{array}{c}\text { No. of Codeable } \\
\text { Responses }\end{array}$ & $\begin{array}{c}\text { No. of Uncodeable } \\
\text { Responses }\end{array}$ & $\begin{array}{l}\text { No. of Non- } \\
\text { Responses }\end{array}$ & Total \\
\hline American & $5222(90 \%)$ & $58(1 \%)$ & 549 (9\%) & 5829 \\
\hline Chinese & 878 (71\%) & $60(5 \%)$ & 293 (24\%) & 1231 \\
\hline
\end{tabular}

Based on the evidence from Wright maps, item fit statistics and student fit statistics, we could make a preliminary conclusion that the American assessments and American carbon cycle learning progression framework appropriately describe and measure the proficiency of Chinese students.

\section{Evidence from comparisons of constructed responses by American and Chinese students}

We compared the written responses from American students with those from Chinese students for specific items to further explore whether American assessments and the American carbon cycle learning progression framework were appropriate for Chinese students. To do this, we chose one to two items from each phenomenon (plant growth and movement, animal growth and movement, burning and decay) and compared the kinds of written responses given by both sets of students.

We found that the majority $(71 \%)$ of Chinese responses (878/1231) were qualitatively similar to the American ones (Table 3). Very few Chinese responses were not codeable. Notably, $24 \%$ of the total Chinese responses were left blank (i.e., "non-response"), compared to only 9\% of total American responses.

\section{Evidence from the patterns in interviews with American and Chinese students}

Like the written assessments, the interviews generally showed that the American learning progression framework could be used to analyze the Chinese students' ways of talking about carbon-transforming processes. Chinese and American students had similar reasoning patterns for each progress variable. This shows that the similarities were apparent in spoken language as well as written responses. A more detailed comparison of American and Chinese students' interview responses is included in the results for Research Question 3, below.

\section{Research Question 2: Comparing Students in Grades 7, 8 and 9}

We compare the overall proficiency of Chinese students in different grades and provide the mean percentage of students' constructed responses at each grade for each learning progression level to explore the differences among them. 


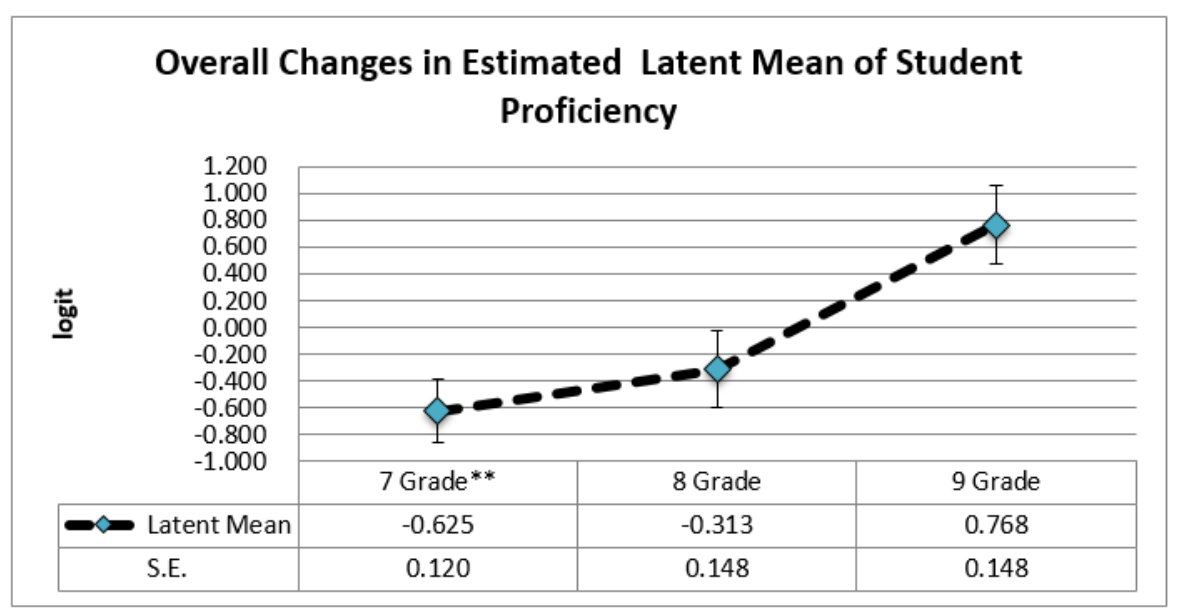

Figure 5. Estimated Latent Mean of Student Proficiency

Table 4. T-test of Chinese Students' Proficiency at Each Grade

\begin{tabular}{cccccc}
\hline Grades & Latent Mean & Mean Difference & Standard Error & t & P-value \\
\hline 7 & -0.625 & & & & \\
8 & -0.313 & 0.312 & 0.148 & 2.108 & $\mathbf{0 . 0 3 6}^{*}$ \\
\hline 7 & -0.625 & & & & \\
9 & 0.768 & 1.393 & 0.148 & 9.412 & $\mathbf{0 . 0 0 0 * *}$ \\
\hline 8 & -0.313 & & & & \\
9 & 0.768 & 1.081 & 0.210 & 5.152 & $\mathbf{0 . 0 0 0}^{* *}$ \\
\hline
\end{tabular}

Note: Mean Difference = (1) Mean of grade 7 students' proficiency-Mean of grade 8 students' proficiency; (2) Mean of grade 7 students' proficiency-Mean of grade 9 students' proficiency; (3) Mean of grade 8 students' proficiency-Mean of grade 9 students' proficiency.

Table 5. The Mean Percentage of Chinese Students' Responses at Each Grade for Each Learning Progression Level

\begin{tabular}{ccccc}
\hline Grades & $\begin{array}{c}\text { Others } \\
\text { (No Answer or Nonsense) }\end{array}$ & Level 2 & Level 3 & Level 4 \\
\hline 7 & $36 \%$ & $\mathbf{4 3 \%}$ & $20 \%$ & $1 \%$ \\
8 & $32 \%$ & $\mathbf{3 4 \%}$ & $\mathbf{3 1 \%}$ & $3 \%$ \\
9 & $18 \%$ & $35 \%$ & $\mathbf{3 7 \%}$ & $\mathbf{1 0 \%}$ \\
\hline
\end{tabular}

\section{The overall proficiency of students in grades 7,8 and 9}

We observed a significant increase in Chinese student proficiencies from grades 7 to 9 (Figure 5). IRT analyses produce estimates of Chinese student proficiencies measured in logits, which are a measure of how likely a student of some proficiency is to get a particular item right or wrong, and the zero logit is set to be the student average.

T-tests showed that the mean difference in overall proficiency between grade 7 and grade 8 students was significantly different, the mean difference in overall proficiency between grade 7 and 9 was significantly different, and the overall proficiency of grade 8 and 9 was also significantly different. Interestingly, we saw the greatest increase in student proficiency in successive years between 8 th and $9^{\text {th }}$ grades, with a smaller, though still significant increase, between $7^{\text {th }}$ and $8^{\text {th }}$ grades (Table 4).

The data in Table 5 were calculated based on the percentage of the Chinese students at each learning progression level (see Appendix C). We found that the majority of the Chinese students at grade 7 were at level 2, the majority of grade 9 students were at level 3 , and the students at grade 8 were divided between levels 2 and 3 .

\section{Research Question 3: Similarities and Differences between American and Chinese Students}

We summarize the similarities and differences between American and Chinese students based on quantitative and qualitative analyses. The quantitative analyses of written tests included comparisons of estimates of students' overall proficiency and analyses of differential item functioning (DIF). Qualitative analyses of students' written and spoken language showed patterns of both similarity and difference. 


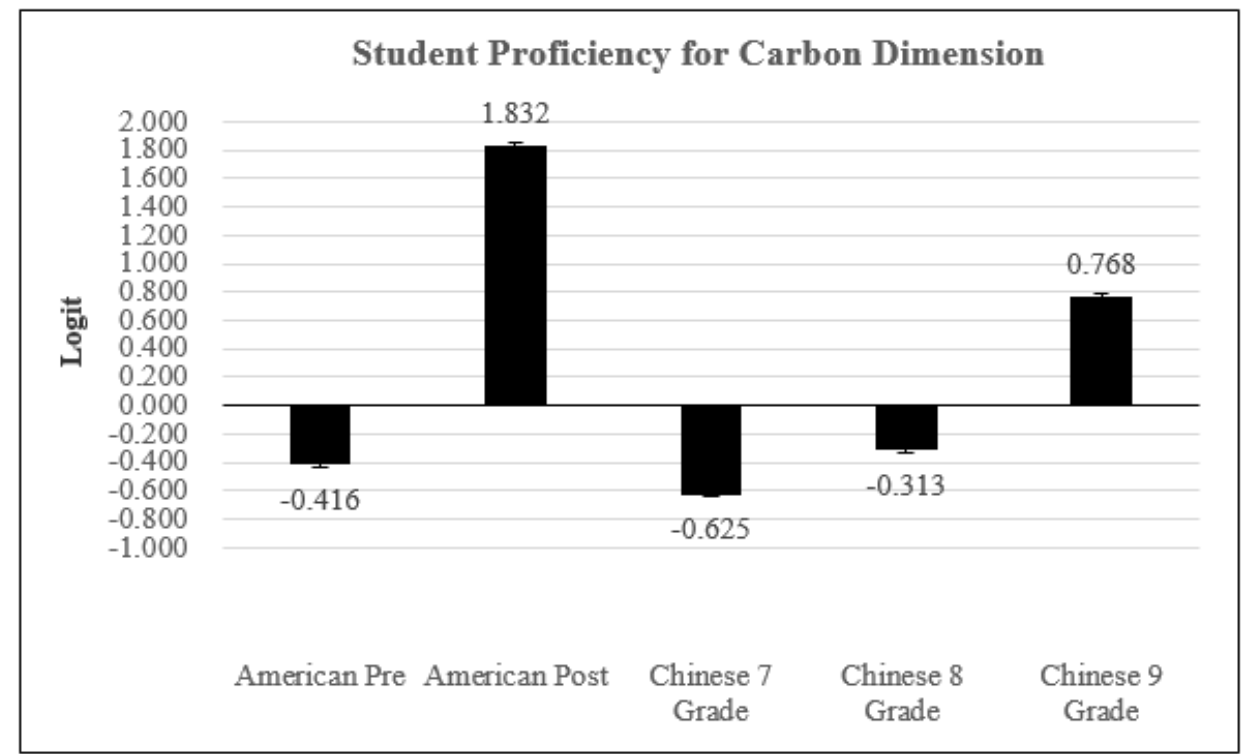

Figure 6. Comparison of Average Proficiencies for Subgroups of American and Chinese Students

Table 6. Interaction between the item and country (Differential Item Functioning) DIF for EX\&TFC

\begin{tabular}{|c|c|c|c|c|c|}
\hline Item & Country & DIF par & S.E. & $\mathbf{z}$ & P-value \\
\hline BREADMOLD.EX & American & -1.158 & 0.153 & -7.569 & 0.000 \\
\hline BRNMATCHEN.EX & American & -0.850 & 0.167 & -5.090 & 0.000 \\
\hline BRNMATCHMAT.EX & American & -0.407 & 0.116 & -3.509 & 0.000 \\
\hline COMPOSTB.EX & American & -0.480 & 0.118 & -4.068 & 0.000 \\
\hline ENERGRASS.EX & American & -0.251 & 0.074 & -3.392 & 0.001 \\
\hline FOODCHAIN4.EX & Chinese* & -0.412 & 0.057 & -7.228 & 0.000 \\
\hline GIRLGROWPARTS.EX & American & -0.304 & 0.118 & -2.576 & 0.010 \\
\hline OAKTREEPARTS.EX & Chinese* & -0.347 & 0.062 & -5.597 & 0.000 \\
\hline OCTAMOLE.EX & Chinese* $^{*}$ & -0.274 & 0.066 & -4.152 & 0.000 \\
\hline BREADMOLD.TFC & Chinese* $^{*}$ & -0.390 & 0.115 & -3.391 & 0.001 \\
\hline BRNMATCHEN.TFC & Chinese* $^{*}$ & -0.346 & 0.051 & -6.784 & 0.000 \\
\hline BRNMATCHMAT.TFC & Chinese $^{*}$ & -0.236 & 0.060 & -3.933 & 0.000 \\
\hline ENERGRASS.TFC & American & -0.227 & 0.044 & -5.159 & 0.000 \\
\hline FATLOSS.TFC & Chinese* $^{*}$ & -0.131 & 0.034 & -3.853 & 0.000 \\
\hline GIRLGROWPARTS.TFC & Chinese* $^{*}$ & -0.134 & 0.059 & -2.271 & 0.023 \\
\hline MATERIALS3.TFC & Chinese* $^{*}$ & -0.288 & 0.055 & -5.236 & 0.000 \\
\hline OAKTREEPARTS.TFC & American & -0.109 & 0.035 & -3.114 & 0.002 \\
\hline OCTAMOLE.TFC & Chinese $^{*}$ & -0.340 & 0.034 & -10.000 & 0.000 \\
\hline POTATO.TFC & Chinese $^{*}$ & -0.152 & 0.035 & -4.343 & 0.000 \\
\hline
\end{tabular}

Note: DIFs in bold represent that items were relatively more difficult for Chinese students than American Pre students; DIFs in italic represent that items were relatively easier for Chinese students than American Pre students.

\section{Similarities and differences between American and Chinese students on written assessments}

American middle school students who took at least three units of the Carbon TIME curricula and then were administrated to posttests were approaching Level 4, while American students' pretests were at Level 2, implying the Carbon TIME curricula considerably improved students' understandings of carbon-transforming processes (Figure 6). And the majority of Chinese students (who only participated in the pretests) were at Level 2, suggesting Chinese and American students had similar average proficiencies (Figure 6).

Analyses of responses for individual items. Six open explanation (EX)-based items were easier for American students, while only three open EX-based items were easier for Chinese students (Table 6). However, two forcedchoice (FC) items were easier for American students, while eight FC items were easier for Chinese students (Table 6).

In addition to the quantitative analyses, we also made qualitative comparisons between the constructed responses of American and Chinese students. Key similarities and differences are summarized below. 


\section{Similarities}

Difficulty connecting systems at different scales. First, many American and Chinese students in our sample could not connect the large or macroscopic scale to the atomic-molecular scale. For example:

- The item BRNMATCHEN asks students where the heat and light energy comes from when a match burns. $53 \%$ of the American students and $29 \%$ of the Chinese students mentioned that because a flame needs air to burn, the air must have the most energy, and the heat and light energy comes from the air; or because the match would never have started to burn without the person, the heat and light energy comes from the person who struck the match. To them, if something is needed, it will provide energy. They only paid attention to the phenomenon at the macroscopic scale.

- The item BODYHEAT2 asks students how food contributes to people's body heat. $53 \%$ of the American students and $32 \%$ of the Chinese students both thought that since we eat food, food is changed to energy. They did not connect the food that people eat at the macroscopic scale to the chemical energy stored in the food at the atomic-molecular scale, explaining this phenomenon only at the macroscopic scale.

Attributing macroscopic properties to atoms and molecules. Second, when American and Chinese students tried to explain a phenomenon by connecting the atomic-molecular scale with the large or macroscopic scale, many students failed to recognize the special properties of atoms and molecules. For example, some American students responded to the item FATLOSS by saying that the atoms in the fat of a person who loses weight shrink or get smaller or decrease in size. Some Chinese students had similar responses. These students used what they know or see at the macroscopic scale to explain what they do not know or cannot see at the atomic-molecular scale. In essence, they interpreted the macroscopic scale and the atomic-molecular scale as being the same.

Distinguishing matter from energy. Third, many American and Chinese students in our sample both were unable to trace matter and energy separately, instead describing implicit or explicit matter-energy conversions. For example:

- The BRNMATCHMAT item asks students why the ashes of a match weigh less than the original match when it burns. $46 \%$ of the American students and $41 \%$ of the Chinese students said that the match or some of the match would turn into heat and light energy as it burns.

- The item FATLOSS asks students what happens to the atoms in a man's fat when he exercises and loses weight. $49 \%$ of the American students and $36 \%$ of the Chinese students thought the atoms in the fat of the person who loses weight are converted into energy or heat. For example, some American students said, "The fat turns into energy when he exercises." Some Chinese students said, "Those atoms will be transformed into energy."

Although American and Chinese students in our sample were generally aware of conservation of matter and energy, many of them did not account for matter and energy separately and apply them to the daily life contexts correctly.

\section{Differences}

The key differences between the American and Chinese students are (1) Chinese students were reluctant to write their ideas when they did not know a scientifically correct answer, while American students were more willing to express their ideas, (2) American students paid more attention to the environmental impact of human behaviors than Chinese students, and (3) Chinese students used chemical equations to explain chemical changes much more often than American students. These key differences are as follows:

Expressing ideas in constructed responses. Overall, 26\% of Chinese students left open response items blank, compared to $9 \%$ of American students for these items. Moreover, the DIF analysis shows that American students were relatively more successful on constructed-response explanation portions of items while Chinese students were relatively more successful on forced-choice responses. These all suggest that Chinese students were reluctant to write their ideas when they did not feel confident that they know a scientifically correct answer.

Environmental awareness. American students wrote more about the environmental impact of human behaviors. For example, the item FLBULBS1112 asks whether using fluorescent light bulbs which use less energy instead of incandescent light bulbs can reduce the amount of carbon dioxide going into our atmosphere. Around $12 \%$ of the American students were able to make connections between burning of fossil fuels/coal and the release of $\mathrm{CO}_{2}$ compared to only $6 \%$ of the Chinese students.

The items ARCTICICEONE and ARCTICICEFIVE ask students to predict how sea ice extent will change in one and five years from November, 2013, and explain why this occurs. Some of the Chinese students explained that global warming or the greenhouse effect caused the decrease of the extent of Arctic sea ice without explaining why, while more American students explained the reasons or described global warming in a detailed way. For example, 
some American students said, "Due to global temperatures rising at an alarming rate, sea ice has dramatically decreased in coverage. This means that in the future arctic sea ice will occur further and further north over a small area." "Earth-friendly inventions are in the process of getting tested. Electric cars and solar panels are in more use now, however, it takes a long time to get sea ice to form again, therefore $11.0 \mathrm{msg}$ is possible, but not likely yet."

Using chemical equations. Chinese students used chemical equations to explain chemical changes much more often compared to the American students. For example, the item OCTAMOLE asks students what happens to the atoms in the octane when it burns inside a car. About $5 \%$ of the Chinese students used chemical equations in their explanations of chemical changes when the octane burns, while only $0.3 \%$ of the American students used chemical equations when answering this item. Notably, Chinese students at level 3 or 4 in our sample often used partially correct or correct chemical equations, while level 3 or 4 American students rarely did.

\section{Similarities and differences between American and Chinese students in interviews}

The majority of interviews with Chinese and American students showed similar patterns for each of four progress variables in the interview protocol, although there were two key differences in the ways these groups of students reasoned (Tables 7 and 8 ).

For the first progress variable, "context-specific knowledge", the majority of American and Chinese students both focused on actors and enablers for a purpose (growth, movement, survival) instead of offering scientific details, and offered limited or wrong knowledge (Table 7). For the second, "orientation towards principles of matter and energy", two groups of students both broken the conservation of matter and energy. For the third, "precision in matter and energy words", students in two countries both lacked understanding of molecules and atoms, misused "nutrients", and conflated matter, energy and nutrients. For the fourth, "scale", students in different groups both omitted the atomic-molecular scale, and used the language of the atomic-molecular scale in ways that treat molecules as macroscopic materials. 
Table 7. Similar Patterns in American and Chinese Students' Interviews Progress Variables And Patterns Interviews from American students

Context-Specific Knowledge
Patterns: (1) Focus on actors and
enablers needed to achieve a
purpose (growth, movement,
survival) instead of offering
scientific details about the
phenomena in question.

Patterns: (2) Offer limited or wrong context-specific knowledge.

\section{Example 1:}

I: So how does the tree use water to grow? supports the tree, basically.

\section{Example 2:}

I: Why does a tree need energy?

S: Because [of] how it grows.

Example: you mean by that?
S: The tree uses water to grow because it takes the water in and then...it takes the water in through its roots and uses it to help with adding leaves. It

I: And by respiration, can you explain to me what

S: Like the exchange of gases.

\section{Example:}

I: Okay. So could you divide the pictures into groups in terms of how matter changes during the event?

Orientation Towards Principles of Matter and Energy Patterns: (1) Matter could be created or destroyed.

S: They're kind of - they would probably be in the same - in about the same way since they would be using - their matter may be going - they would be creating matter.

Patterns: (2) Energy is associated with being alive, and disappears with death.

I: Of the three [carbon dioxide, gasoline, and dead wood], which would you say has the most stored energy?

S: [carbon dioxide, gasoline] have more stored energy maybe because the deadwood now that it dead is like lost its energy.

\section{Example:}

I: So you're saying the cells are made up of atoms? S: Yes.

I: And do you know what atoms are made up of? S: Molecules.

\section{Precision in Matter and Energy Example:}

Words

I: How does the tree use water to grow?

Patterns: (1) Lack understanding S: The tree uses water to grow the same way that of molecules and atoms. we use water. It takes it in, it brings it to the cells, make the cells healthy, and also makes the cells be Patterns: (2) Use "nutrients" as able to flow through the tree with ease. And makes something that makes organisms it be like the carrier of nutrition through the trees.

alive and healthy instead of I: Carry what? specific molecules.

S: Carry nutrition.

Example:

Patterns: (3) Conflate matter, I: Does it [energy] change into other things and energy and nutrients.

S: ..When it changes into glucose with the chloroplast and the sun chemical change then it goes out through the tree then it goes through the glucose just providing nutrients for the rest of the tree.
Interviews from Chinese students

Example 1:

I: How does the tree use water to grow?

S: Roots take water in and deliver water

to each leaf. Therefore leaves can keep fresh and not dry out.

Example 2:

I: Why does a tree need energy?

$\mathrm{S}$ : The tree needs energy to grow.

Example:

I: Can you explain what respiration is?

S: I can't remember, I guess it's also a process of breathing in $\mathrm{CO}_{2}$, or something like that.

\section{Example:}

I: Can you explain each group [baby girl growing, tree growing, girl jumping; flame burning, car running; tree decaying]?

$\mathrm{S}$ : The matter during baby girl growing, tree growing, and girl jumping changes and increases. The matter during flame burning and car running burns up and disappears. The matter during the tree decaying also decreases.

Example:

I: Why did you think dead wood, sand, glass, oxygen and $\mathrm{CO} 2$ have less stored energy?

$\mathrm{S}$ : Because the dead wood is already dead, I don't think it plays a great role in the nature..

\section{Example:}

I: Are there atoms in leaves?

$\mathrm{S}$ : I don't know what atom is.

I: What molecules are included in the leaves?

S: I have no idea.

Example:

I: Ok, let's move to the next question. The tree gains weight as it grows. Suppose the tree gains one kilogram of wood. Where does that one kilogram of wood come from?

S: It comes from nutrients.

I: What do you mean by nutrients?

S: Nutrients in the soil and air.

Example:

I: Is it still energy? Or does it change into other things? $\mathrm{S}$ : It will change into other things.

I: How to change?

$\mathrm{S}$ : The energy goes into the cell, and change into the nutrients in the cell.

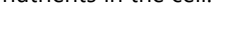

\section{Example:}

Patterns: (2) Use the language of the atomic-molecular scale, but in ways that treat molecules as macroscopic materials that either stay intact or change from one material to another during processes.
I: So where does the energy go inside the tree?

$\mathrm{S}$ : Well, when it is absorbed through the leaves it

has photosynthesis in the leaves and it basically

becomes food for the tree.

Example:

I: So how does [the tree] use $\mathrm{CO} 2$ to grow?

\section{Example:}

I: How does the tree use sunlight to grow?

$\mathrm{S}$ : It uses sunlight to do photosynthesis to produce nutrients.

Example:

I: Do you think that anything is going out of the leaf cells as the leaf grows?

$\mathrm{S}$ : Well that's like our oxygen. We breathe in and we $\mathrm{S}$ : Waste and oxygen.

breathe out carbon dioxide. It breathes in the

I: How is the oxygen produced?

carbon dioxide and then breathes out oxygen. It's S: The plant breathes in CO2 and turns it into oxygen in

kind of like its lungs takes it in and then uses that as $\mathrm{S}$ : The plant

Note: "I" represents "Interviewer", "S" represents "Students" 
Table 8. Different Patterns in American and Chinese Students' Interviews

\begin{tabular}{|c|c|c|}
\hline Patterns & Interviews from American students & Interviews from Chinese students \\
\hline $\begin{array}{l}\text { Structures and Functions VS. } \\
\text { Hierarchy of Structures }\end{array}$ & $\begin{array}{l}\text { Example: } \\
\text { I: So what are cells made of? } \\
\text { S: Well, they have cell walls and they have a } \\
\text { nucleus and since it's a leaf it can perform } \\
\text { photosynthesis so it has chloroplast where } \\
\text { photosynthesis will take place. } \\
\text { I: So what are all those things made of? } \\
\text { S: Just...well, they're made from the glucose } \\
\text { that the plant can produce in } \\
\text { photosynthesis. } \\
\text { I: And so what is the glucose made of? } \\
\text { S: Carbon, hydrogen and oxygen. }\end{array}$ & $\begin{array}{l}\text { Example: } \\
\text { I: What are cells made of? } \\
\text { S: Cell wall, cell membrane, cell nucleus, } \\
\text { chloroplast and vacuole. } \\
\text { I: What is cell nucleus or vacuole made of? } \\
\text { S: The tissues in themselves. } \\
\text { I: What are these tissues made of? } \\
\text { S: Water, and protein, or maybe there is not } \\
\text { protein. } \\
\text { I: What is water made of? } \\
\text { S: Molecules, oxygen molecule, I heard it before. }\end{array}$ \\
\hline Size VS. Numbers & $\begin{array}{l}\text { Example 1: } \\
\text { I: Does that gas exchange do anything to help } \\
\text { with growing for the tree? Is there a } \\
\text { connection there? } \\
\text { S: ...I don't know. Maybe one way of it allows } \\
\text { oxygen and carbon dioxide to move through } \\
\text { the tree. And the more it breathes in, the } \\
\text { more space it needs to clean it or whatever it } \\
\text { does, and let it out. So that could affect the } \\
\text { growth. } \\
\text { Example 2: } \\
\text { I: Okay. Do you think that anything is going } \\
\text { into or out of the leaf cells as the leaf grows? } \\
\text { S: Yes. I think when the cells expand, it gets } \\
\text { a space in between like the cells walls are } \\
\text { getting thinner and thinner and thinner } \\
\text { because they're expanding... }\end{array}$ & $\begin{array}{l}\text { Example 1: } \\
\text { I: What do the leaf cells do as the leaf grows? } \\
\text { S: The numbers of cells increase. The } \\
\text { substances in cells increase. } \\
\text { I: Which substances will increase? } \\
\text { S: For example, vacuole and chloroplast. } \\
\text { Example 2: } \\
\text { I: What do the leaf cells do as the leaf grows? } \\
\text { S: The numbers of cells will increase. }\end{array}$ \\
\hline
\end{tabular}

Note: "I" represents "Interviewer", "S" represents "Students"

There were two key differences in the ways Chinese and American students reasoned about carbontransforming processes (Table 8).

Structure and function vs. Hierarchy of structures: One general pattern is that American students gave more explanations that related structures to functions, while Chinese students frequently described hierarchies of structures, meaning their answers included more structures at different scales rather than how those structures work.

Size vs. Numbers: Another general pattern is that when students explain how organisms grow, American students described things growing mainly because they expand or get bigger, while Chinese students explained the main reason why organisms grow was because the numbers of substances in them increased.

\section{DISCUSSION AND IMPLICATIONS}

The results suggested that the American and Chinese students both have some problems constructing modelbased explanations of carbon-transforming processes. In this section, we hypothesize about reasons for these problems, suggest solutions to improve students' understanding of carbon-transforming processes, and propose improvements in science education in each country.

\section{Discussion}

Some conclusions were drawn from the similarities and differences between the American and Chinese students, and the underlying causes for them are discussed.

\section{Most American and Chinese students do not trace matter and energy separately when they explain carbon-transforming processes}

One reason students struggle with tracing matter and energy separately is that they have difficulty connecting knowledge in one discipline to the knowledge in another. This is especially true for energy, where students learn energy concepts and energy conservation principles in their physical science classes, then have problems applying 
the energy-related knowledge to biology. Secondly, it is difficult for students to understand how energy transformation works. They learn simple organic reactions, and chemical change which happens in simple physical contexts, but chemical change in complex biological contexts is challenging and requires teacher assistance. Finally, the crosscutting concept (energy and matter: flows, cycles, and conservation) is not emphasized in the curriculum, so teachers rarely emphasize helping students understand how energy flows in biological systems. Therefore, students struggle to trace energy in biological contexts.

\section{American and Chinese students need to learn how to connect systems at different scales when they construct explanations of carbon-transforming processes}

We suggest one reason students have problem connecting systems at different scales is because the crosscutting concepts (especially, scale, proportion and quantity; systems and system models) are less privileged in curriculum and students have only limited opportunities to understand and apply those crosscutting concepts in biological systems. In thinking scientifically about processes and systems, students need to recognize that biological processes and systems happen in a hierarchy of systems at different scales.

\section{American and Chinese students have different explanatory ideals for structures and growth of organisms}

Previous research (Hesse \& Anderson, 1992; Toulmin, 1961) suggested that different people and cultures have different notions of what a good or satisfying explanation includes, what Toulmin referred to as explanatory ideals. If the explanatory ideal is different, the explanations based on it are also different. For many Chinese students at lower levels, a satisfying explanation for describing what cells are made of should include all structures at different scales inside cells, while American students think naming core structures and describing functions of those structures is a good explanation. The difference in explaining how organisms grow suggested size-related explanations for growth are explanatory ideals for American students, while for Chinese ones number is much more important than size.

Therefore, American and Chinese students have some different explanatory ideals when they explain the structures and growth of organisms. Thus when we think about what a good explanation is, one thing we need to consider is the effect of school curricula in different countries on students' explanatory ideals.

\section{Chinese students are more reluctant to write their informal ideas}

The results showed that one of the differences between American and Chinese students is more Chinese students chose to leave the question blank when they did not know the answer, while more American students were willing to answer questions, even if incorrect. The American and Chinese students have different cultures and science education systems. Our assumption is that the Chinese culture and exam system may have a strong impact on Chinese students' responses.

Education is aligned with culture because education is itself a component of culture. Since traditional Chinese culture holds Confucian culture at its core, Confucianism influences every aspect of traditional Chinese education, from educational philosophies and values to educational content and methodologies of education (Gu, 2013). The Confucian-heritage culture and educational values have both positive and negative sides. Regarding the negative sides, some scholars have commented that one word could summarize Chinese education over thousands of years: obedience $(\mathrm{Gu}, 2013)$. Overemphasis on obedience means that students are hesitant to think, speak, or explore new paths. Therefore, we assume that lots of Chinese students in our study may feel uncomfortable venturing a new idea and worry that they may be incorrect if they give a new idea, so left the answer blank.

Additionally, the exam-oriented education system in China emphasizes high-stakes testing, and the aim of learning mainly focuses on passing examinations. In China, students face numerous examinations as soon as they start their schooling (Qi, 2004). Examinations play a pivotal role in student success. Focusing solely on exams often comes at the cost of students losing their critical thinking, imaginations and creativities (Schmitz, 2011). In the Chinese exam system, mastery of scientific knowledge is more privileged, while innovation is less privileged. In addition, exams in China are primarily summative assessments that focus on formal scientific knowledge. Although there are some tasks and tests in classrooms that elicit students' informal understanding and explore their initial thinking about things that happen in their daily life, students' informal understanding and formative assessment are less privileged.

However, the tests in the Carbon TIME project focus on students' informal and formal reasoning, innovative thinking, explanations about new phenomena, and using models to address new problems. The tests in the Carbon TIME project and typical Chinese exams thus have different goals and expectations for students. Therefore, the 
Chinese students who are used to exams that emphasize contributions of scientific knowledge in formal language may be more likely to leave a question blank rather than venture an idea based on their informal knowledge.

However, we must note that the assessment instructions given to American and Chinese students were different, which may explain why many Chinese students did not write anything as answer for items. The instructions for the American students encouraged students to express their ideas and write anything that they wanted to say, while the instructions for the Chinese students just mentioned that students needed to write answers on the answer sheet, rather than also encouraging students to express their thinking and ideas boldly.

\section{Chinese students need to know more about the connections between science and environmental or social issues}

Another difference between the American and Chinese students in this work was more Chinese students wrote less about the relationship between ecosystems and human beings than American students. The relationship between human activities and the release of carbon dioxide, and the negative effect of the excessive amount of carbon dioxide on the global ecosystem, were rarely included less in the textbooks of Chinese students. In order to better develop students' environmental literacy, it's imperative for Chinese science educators to emphasize science topics that have important environmental and social impacts.

\section{Implications}

There are many similarities between the ways that Chinese and American students make sense of carbontransforming processes, suggesting that learning progression (LP) frameworks and assessments developed in one country can be useful in the other. Moreover, neither country has middle school curricula and teaching strategies that are successfully enabling three-dimensional learning for most students, giving us opportunities to reach our potential for working together to develop three-dimensional learning in different countries. The significant differences in performances between pretests and posttests for American students in this research suggest the Carbon TIME curriculum is effective for improving American students' three-dimensional learning, implying this curriculum could also work for Chinese students. The Carbon TIME curriculum includes six units: (1) The foundational unit (Systems and Scale) orients students to the foundational perspectives and routines for the core concepts addressed; (2) The three organism-scale units (Animals, Plants, Decomposers) focus on transformations in matter and energy at the organism level; (3) The two large-scale units (Ecosystems, Human Energy Systems) build on the concepts developed in the previous units to address carbon cycling and energy flow at ecosystem and global scales (http:/ / carbontime.bscs.org/).

The American science education reform movement emphasizes three-dimensional learning, which is the integration of content knowledge, crosscutting concepts and practices. Our research indicates two notable challenges for students when constructing model-based explanations: They do not trace matter and energy separately or connect systems at different scales, which are both crosscutting concepts in the three-dimensional learning framework that is used for the American Next Generation Science Standards (NGSS Lead States, 2013). Currently, curriculum reform movements in the United States emphasize that students need opportunities to experience the use of crosscutting concepts and practices in multiple contexts in order to develop their capacities to address new problems, which is an important goal of science learning (National Research Council, 2000, 2007). Our work suggests curricula should emphasize integrating the crosscutting concepts into the curriculum and engaging students in practices using crosscutting concepts.

Based on our work, Chinese science teaching and learning can also benefit from this approach because many Chinese students also struggle to use crosscutting concepts, and practice using crosscutting concepts or rules they are not familiar with to address novel issues that they have never met before. Chinese educators need to think about whether they should care about and carry out the three-dimensional learning.

Furthermore, to make improvements in science education in each country, another needed reform is to improve education assessment systems. One way to do this is to use learning progressions. The assessments in the Carbon TIME project interpret students' responses using the learning progression framework; the assessments also use tools and activities to grade students' responses and give students the summative tests. Learning progressions focus on students' informal and formal scientific ideas and provide useful tools for formative and summative assessments.

However, because educational assessment systems are being perceived less as a technical matter of measurement and more as a sociocultural practice of teachers and students in the classroom, assessment systems are embedded in social and cultural contexts. Many American teachers still struggle to understand threedimensional learning and effectively apply it to classrooms in a scientifically rigorous way (National Research Council, 2000, 2007; Thompson, Hagenah, Kang, Stroupe, Braaten, Colley, \& Windschitl, 2016). For example, 
regarding formative assessment, we need to think how to transfer the formative assessment used to improve science teaching and learning in the Western educational systems to the Chinese context.

\section{LIMITATIONS}

First, although we provided qualitative and quantitative evidence that the American learning progression framework and assessments could be used to describe and measure the proficiency of Chinese students, the conclusions may not be applicable to all Chinese students since the number of sample students was limited. Second, in the current analysis, the number of Chinese students who participated in interviews was limited. We suggest further interviews to discover more patterns in Chinese students' reasoning. Lastly, the written assessment instructions given to American and Chinese students were different, which may affect Chinese students to express their thinking and ideas boldly to some extent.

\section{ACKNOWLEDGEMENT}

The authors would like to thank the entire Carbon TIME project team for their support of this study. The authors gratefully acknowledge the students, science teachers and schools that assisted with the data collection.

This research is supported in part by a grant from the National Science Foundation: Sustaining Responsive and Rigorous Teaching Based on Carbon TIME (NSF 1440988). Any opinions, findings, and conclusions or recommendations expressed in this material are those of the author(s) and do not necessarily reflect the views of the National Science Foundation.

\section{REFERENCES}

Fleiss, J. L., \& Cohen, J. (1973). The equivalence of weighted kappa and the intraclass correlation coefficient as measures of reliability. Educational and psychological measurement, 33(3), 613-619. https:/ / doi.org/10.1177/001316447303300309

Giere, R. (1988). Explaining science: A cognitive approach. Chicago University Press, Chicago. https:// doi.org/10.5860/choice.26-2103

Gilbert, J. K. (2004). Models and modelling: Routes to more authentic science education. International Journal of Science and Mathematics Education, 2(2), 115-130. https:/ / doi.org/10.1007/s10763-004-3186-4

$\mathrm{Gu}$, M. Y. (2013). Influence of traditional Chinese culture on Chinese education. In Cultural Foundations of Chinese Education (pp. 89-127). Leiden, Netherlands: Brill Academic Publishers. https:// doi.org/10.1163/9789004263161

Hesse, J. J., \& Anderson, C. W. (1992). Students' conceptions of chemical change. Journal of Research in Science Teaching, 29(3), 277-299. https:/ / doi.org/10.1002/tea.3660290307

Irribarra, D. T., \& Freund, R. (2014). Wright Map: IRT item-person map with ConQuest integration, R Package "WrightMap". Retrieved from https://cran.r-project.org/web/packages/WrightMap/WrightMap.pdf

Jin, H., \& Anderson, C. W. (2012). A learning progression for energy in socio-ecological systems. Journal of Research in Science Teaching, 49(9), 1149-1180. https:/ / doi.org/10.1002/tea.21051

Jin, H., Zhan, L., \& Anderson, C. W. (2013). Developing a fine-grained learning progression framework for carbontransforming processes. International Journal of Science Education, 35(10), 1663-1697. https:/ / doi.org/10.1080/09500693.2013.782453

Justi, R. S., \& Gilbert, J. K. (2002a). Modelling, teachers' views on the nature of modeling, and implications for the education of modellers. International Journal of Science Education, 24(4), 369-387. https://doi.org/10.1080/09500690110110142

Lin, C. Y., \& Hu, R. (2003). Students' understanding of energy flow and matter cycling in the context of the food chain, photosynthesis, and respiration. International Journal of Science Education, 25(12), 1529-1544. https:/ / doi.org/10.1080/0950069032000052045

Masters, G. N. (1982). A Rasch model for partial credit scoring. Psychometrika, 47(2), 149-174. https://doi.org/10.1007/bf02296272

Miller, H. K., Johnson, W. R., Freed, A. W., Doherty, J. H., \& Anderson, C. W. (submitted, 2017). Crosscutting concepts for re-orienting science education. Submitted to Science Education.

Mohan, L., \& Anderson, C. W. (2009). Teaching experiments and the carbon cycle learning progression. Paper presented at the Learning Progressions in Science (LeaPS) Conference, Iowa City, IA. 
Mohan, L., Chen, J., \& Anderson, C. W. (2009). Developing a multi-year learning progression for carbon cycling in socio-ecological systems. Journal of Research in Science Teaching, 46(6), 675-698. https://doi.org/10.1002/tea.20314

Mohan, L., Chen, J., Baek, H., Anderson, C. W., Choy, J., Lee Y.S. (2009). Validation of a multi-year carbon cycle learning progression: a closer look at progress variables and processes. Paper presented at the annual meeting of NARST, Garden Grove, CA.

National Research Council. (2000). How people learn: Brain, mind, experience, and school. Washington, DC: The National Academies Press. https:/ / doi.org/10.17226/9853

National Research Council. (2007). Taking science to school: Learning and teaching science in grades K-8. Washington, DC: The National Academies Press. https:/ / doi.org/10.17226/11625

National Research Council. (2012). A Framework for K-12 Science Education: Practices, Crosscutting Concepts, and Core Ideas. Washington, DC: The National Academies Press. https:/ / doi.org/10.17226/13165

National Research Council. (2014). Developing assessments for the next generation science standards. Washington, DC: The National Academies Press. https:/ / doi.org/10.17226/18409

NGSS Lead States. (2013). Next generation science standards: For states, by states. Washington, DC: National Academy Press. Retrieved from https://www.nextgenscience.org/sites/default/files/AllDCI.pdf

Qi, L. (2004). Has a high-stakes test produced the intended changes? In L. Cheng, \& Y. Watanabe (Eds.), Washback in language testing: Research contexts and methods (pp. 171-190). Mahwah, N.J.: Laurence Erlbaum \& Associates. https:/ / doi.org/10.4324/9781410609731

Schmitz, R. (2011). The downside of exam-based education in China. Marketplace. Retrieved from http:/ / marketplace.publicradio.org/display/web/2011/06/07/ pm-thedownside-of-exambasededucation-in-china/

Stern, L., \& Ahlgren, A. (2002). Analysis of students' assessments in middle school curriculum materials: Aiming precisely at benchmarks and standards. Journal of Research in Science Teaching, 39(9), 889-910. https://doi.org/10.1002/tea.10050

Thomas, J., Kim, J. H., \& Draney, K. (2018). Machine scoring and IRT analysis. Paper presented at the annual meeting of NARST, Atlanta, GA.

Thompson, J., Hagenah, S., Kang, H., Stroupe, D., Braaten, M., Colley, C., \& Windschitl, M. (2016). Rigor and responsiveness in classroom activity. Teachers College Record, 118(5), 1-58. Retrieved from https:/ / www.tcrecord.org/ content.asp?contentid=19366

Toulmin, S. (1961). Foresight and understanding. Great Britain: The Anchor Press.

Wright, B. D., Linacre, J. M., Gustafsson, J. E., \& Martin-Loff, P. (1994). Reasonable mean-square fit values. Rasch Measurement Transactions, 8(3), 370. Retrieved from https://www.rasch.org/rmt/rmt83b.htm

Wu, M. L., Adams, R. J., Wilson, M. R., Haldane, S.A. (2007). ACER ConQuest 2.0 Manual [computer program]. Hawthorn, Australia: ACER.

Zangori, L., Forbes, C. T. (2015). Exploring third-grade student model-based explanations about plant relationships within an ecosystem. International Journal of Science Education, 37(18), 2942-2964. https:/ / doi.org/10.1080/09500693.2015.1118772

Zangori, L., Forbes, C. T., Schwarz, C. V. (2015). Exploring the effect of embedded scaffolding within curricular tasks on third-grade students' model-based explanations about hydrologic cycling. Science E Education, 24, 957-981. https:/ / doi.org/10.1007/s11191-015-9771-9 


\section{APPENDIX A}

\section{Interview Protocol}

\section{Interview Protocol for Carbon TIME Project}

\section{Preparation for Interview}

Before you start, clearly articulate to yourself what specific information needs to be gathered about the student's learning in order to be useful for research. This helps you keep clear focus on the intent of each question. As an interviewer, it may be useful to ask clarifying and follow-up questions to the student that are unscripted in order to fully investigate their thinking. Examples of good questions are "what do you mean by that?" "Could you summarize that answer for me again?" "Could you tell me in terms of [matter and energy] or [atoms and molecules]? Examples of bad questions are "And the name of that process is...?" "Remember how we did something like this in class?" These are very leading questions and tend to preclude many possible types of student responses.

Choose a setting with little distraction. Don't conduct multiple interviews in one room. Please make sure that the camcorder captures your interviewee's voice clearly. If an interview has very bad sound quality, it will not be useful for analysis. Please make sure that you find a quiet room for interview.

If you use an external microphone with the camera, don't forget to turn it on! If you have time, check for sound quality by recording a short segment and playing it back. Be sure that both you and the student can be heard clearly.

Possible things to explain to the student:

- The purpose of the interview is to understand how you explain processes in nature at this point in your learning. Don't be concerned about answering the question correctly as this will not be graded. I'd like you to tell me all that you can about what you know, and how you know it, even if you're unsure.

- I can't give you feedback about right and wrong during the interview, but at the end of the interview I can answer any questions you may have about our conversation.

- I will ask you sets of related questions, and I might take some time while I think about your response. I may also ask questions that sound repetitive, but I'm just trying to be sure that I've covered all the questions that I need to ask.

- This interview should take about 45 minutes. Do you have any questions before we get started? 


\section{Interview Questions}

\section{Matter Association Questions: How Materials are Alike and Different}

Purpose of the questions: How do students connect and relate different items? What kinds of materials do students relate to one another, and why? Do they associate organic and inorganic materials together? Or do they see items as connected in other ways? How do they understand the role of energy in common systems?

Student Practices: Materials, Energy, (Mass/gases, Subsystems, Carbon cycling)

Use Cards for Matter Association Questions (10 cards -muscles in a cow, soil, oxygen, carbon dioxide, water, living branches, dead wood, gasoline, glass, sand)
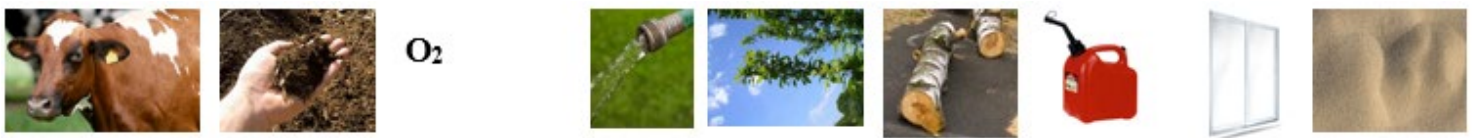

$\mathrm{CO}_{2}$

Reminder: Be sure to say aloud how the student grouped the pictures so that it will be recorded in the written transcript. Also say the name of the picture aloud any time a student is referring to one card in particular.

Interview Script:

1. [Open prompt. Ask students to examine the 10 cards.]

"Each of these cards represents a item. Can you sort these cards into groups of items that are alike? Explain each group. How are the items in each group alike? Does any item within the group not fit as well as the other items? Why? How are the groups different from one another?"

2. [Materials prompt]

"Suppose you think about the MATERIALS the different items are made of, and NOT how the items are used or related in other ways. Can you sort them into groups based on how the MATERIALS are alike and different?

a. Explain each group. How are the items in each group alike? How are the groups different from one another?"

b. [Specific materials probe: Pick out the cards for $\mathrm{CO}_{2}$, gasoline, and dead wood.]

i. "Can you think of any ways that these materials are all alike? How?"

ii. "Can you think of ways that these materials are different? How?"

3. [Energy prompt]

"Let's talk about energy: Are there differences in these materials in the amount of energy they have stored? Which ones have more stored energy?"

How are the items that have more stored energy alike? How are the items that have less stored energy different?"

a. [Specific energy probe: Pick the cards for living branches, dead wood and cow muscle.]

i. "Can you think of ways that these materials are alike with respect to energy? How?"

ii. "Can you think of ways that these materials are different with respect to energy? How?" 


\section{General Tracing Questions: Tree Growing}

Purpose of the questions: We want to know how students explain trees (and plants more generally) growing. What "enablers" do students think are needed for the tree to grow? How do students think about trees and gasexchange? Upper level students will know that the majority of tree biomass came from carbon in the air. Water from the soil is an important input, as are small amounts of minerals from the soil (many students dramatically overestimate the amount of soil minerals taken up by plants). The tree takes in $\mathrm{CO}_{2}$ and releases $\mathrm{O}_{2}$ during photosynthesis. The tree takes in $\mathrm{O}_{2}$ and releases $\mathrm{CO}_{2}$ during respiration. Leaves exchange $\mathrm{CO}_{2}$ for $\mathrm{O}_{2}$ while in sunlight, but all parts of the plant exchange $\mathrm{O}_{2}$ for $\mathrm{CO}_{2}$ continually.

Student Practices: Materials, Mass/gases

You could choose to show this image, tree growth, a card used in the Cross-process Question VI.

Interview Script:

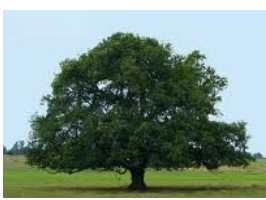

1. [Elicit a list of enablers: air, water, soil (nutrients), and sunlight.]

"What does the tree need in order to grow?"

2. [For enablers not listed by students ask the following until all enablers, sunlight/soil/water/nutrients, are mentioned.]

"Other students told me that the tree needs X to grow. Do you agree?"

3. [Follow up with specific probes about role of all the enablers in growing.]

"How does the tree use air to grow?"

"How does the tree use water to grow?"

"How does the tree use soil (nutrients) to grow?"

"How does the tree use sunlight to grow?"

4. "Does a tree do anything with the air that surrounds it?"

[Possible alternate wording for lower-level students: Does the tree breathe?]

"What does it do? (How does it do that?) What gases are involved?"

5. "Is there a connection between exchanging gases (breathing) and growing for the tree?" [If student says yes] "What is the connection?" 


\section{Inquiry Questions}

Purpose of the questions: We want to know which elements of a scientific argument are most important and valid to a student. We present two scientific arguments and two types of evidence related to each argument and ask the student to critique both.

Student Practices: Inquiry

[Show the image of Mike and Karen silhouettes.]

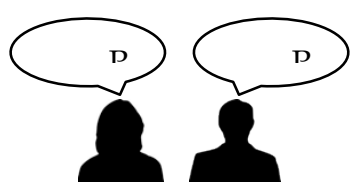

"We are interested in how people use evidence to support their ideas. We're going to talk about two students who disagree with each other about how plants gain weight when they grow. One student Karen said: "The plant gains most of its weight from materials that came from the air.'

"Another student, Mike said: 'The plant gains most of its weight from materials that came from nutrients in the soil.'

1. "Who do you think is right?"

"Now let's talk about the quality of their arguments that support their idea." [Start with the argument that the student agrees with; either Karen or Mike could be first. Show the card associated with Karen or Mike one at a time.]

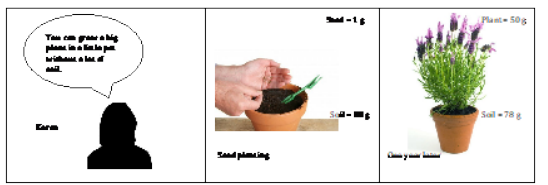

Karen who you [agree/disagree] with, explains,

'You can grow a big plant in a little pot without a lot of soil.' Karen adds some evidence to her argument and explains 'A seed weighing $1 \mathrm{~g}$ was planted in $80 \mathrm{~g}$ of soil. After two years the plant weighted $50 \mathrm{~g}$ and the soil weighed $78 \mathrm{~g} . '$

1. "Can you explain Karen's argument?"

2. "How does Karen's argument support her idea that the plant gains weight from materials that came from the air?"

3. "Are their some weaknesses in Karen's argument? Explain what they are."

4. What evidence would strengthen Karen's argument?

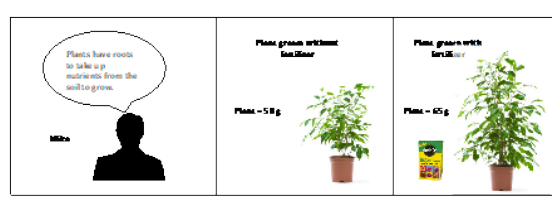

Mike who you ___ [agree/disagree] with explains, 'Plants have roots to take up nutrients from the soil to grow.' Mike adds some evidence to his argument and explains 'A plant grown with no fertilizer weighted $50 \mathrm{~g}$, and a plant grown with fertilizer weighted 65 g.'"

5. "Can you explain Mike's argument?"

6. "How does Mike's argument support his idea that plant gains weight from materials that came from the soil?"

7. "Are their some weaknesses in Mike's argument? Explain what they are."

8. What evidence would strengthen Mike's argument? 


\section{Mass and Energy Tracing Questions}

Purpose of the questions: We want to know if students can trace matter (carbon atoms) from the air into tree mass. An upper-level student will be able to tell you that the mass of the tree is mostly from carbon dioxide (and water). The tree's body is made largely of glucose and cellulose, which are changed from carbon dioxide and water in photosynthesis. The air around the tree loses mass as the tree takes up carbon dioxide. We also want to know if students can trace sunlight energy from the sun to chemical energy stored in the bonds of C-C and C-H molecules (carbohydrates) in the plant.

Student Practices: Mass/gases, Energy, (Materials, Subsystems)

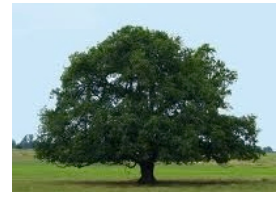

\section{Interview Script:}

1. "The tree gains weight as it grows. Suppose the tree gains exactly one pound of wood. Where does that one pound of wood come from?"

2. "Does something in the tree's environment have to lose weight in order for the tree to gain weight?"

[Alternative explanation for lower level students: "When you gain weight, you use the food you eat, so it loses weight. Is there anything like that for the tree-the tree uses it so that it loses weight when the tree grows?"]

[If the students answers "yes."] "What loses weight when the tree gains weight?

If the tree gains exactly one pound, can you predict how much weight [the materials named by the student] will lose?"

3. "What parts of the tree's environment will lose weight? How much?"

4. "Do you think that the tree needs energy?"

[If yes] "Where does the tree get its energy? Out of the things that you named before [sunlight/soil/water/nutrients], which ones are sources of energy for the tree?"

5. "What is the difference between the things that give the tree energy and the things that don't?"

6. "Do different things give the tree different kinds of energy? Explain."

7. "Why does a tree need energy? Where does that energy go inside the tree? Is it still energy? Does it change into other things? How?" 


\section{Cross Process Questions: Comparing Events}

Purpose of the questions: Similarly to the previous interview question sorting materials, here we ask the student to sort processes. Do students connect certain processes together? Do they see similarities or patterns in certain processes? Upper-level students may say that the tree growth involves the creation of organic carbon molecules. All the other processes involve using organic carbon molecules for energy. The flame burning and car running are both combustion. The girl jumping, baby girl growth and tree decaying all involve respiration. The tree growth and baby girl growth both involve biosynthesis. The tree growth decreases the amount of carbon dioxide in the air surround the leaves, all the other processes increase the carbon dioxide in the air. Student Practices: Energy, Materials, Carbon cycling, Subsystems

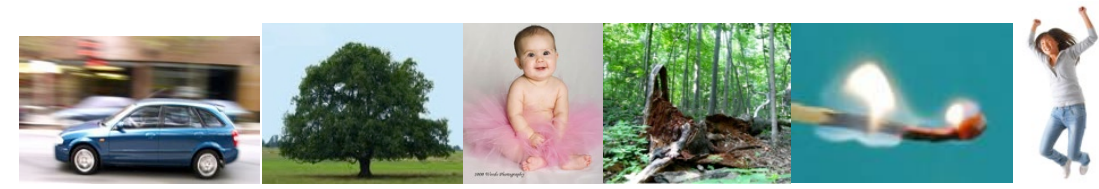

\section{Interview Script:}

[Use the cards for cross process questions (6 cards - car running, tree growing, baby girl growing, girl jumping, tree decaying, flame burning). Show the 6 cards and tell the student what is happening in each card. Explain: Each of these pictures is about an event: Something is happening.]

1. "Can you divide the pictures into groups in terms of events that are alike and different? Explain each group."

2. "Can you divide the pictures into group in terms of how matter changes during the event? Explain each group"

3. "Can you divide the pictures into groups in terms of how energy changes during the event? Explain each group"

4. "Can you divide the pictures into groups in terms of ways of changing or using air during the event? Explain each group." 


\section{Cross Process Questions: Ecosphere}

Purpose of the questions: Students may be able to talk about particular processes like photosynthesis or respiration, but have a difficult time applying these processes to an ecosystem setting. Connections between multiple processes are important to understanding the movement of matter and the flow of energy in ecosystems. Upper-level students may be able to say that:

The algae, shrimp and bacteria rely on each other to survive. The algae photosynthesize by taking $\mathrm{CO}_{2}$ from the air and create new cells as they grow. The shrimp eat the algae and produce $\mathrm{CO}_{2}$ as they respire and nutrients as waste. The bacteria eat the waste from the shrimp and also produce $\mathrm{CO}_{2}$ as they respire. All of the organisms need water and oxygen and mineral nutrients, all of which are recycled throughout the ecosphere.

The ecosphere does exchange energy with the outside environment rather than just recycle energy within the ecosphere. Light allows the algae to photosynthesize and store energy in carbon bonds. All of the organisms use energy as they grow, move and metabolize, and energy is released from the ecosphere as heat that is produced whenever organic carbon changes form.

Student Practices: Carbon cycling, Energy

\section{Interview Script:}

[Use the card for ecosphere question]

[Tell the Student:] "NASA scientists invented the EcoSphere - inside a completely sealed glass container, (there is no opening at the top of the jar!) there are air, water, gravel, (the branch-like thing is just for show) and three living things - algae, shrimp, and bacteria. (Identify the shrimp and algae as the green parts like a plant, you can't see the bacteria.) Usually, these three living things can stay alive in the container for two or three years until the shrimp become too old to live. The picture above shows an EcoSphere and it's inside parts. The EcoSphere is a closed ecosystem and has no exchange of matter with the outside environment." Note: be sure to mention that the algae are like a plant.

1. "How can the algae/shrimp/bacteria stay alive? Do you think algae/shrimp/bacteria can get everything it needs? What are those things? Where do they come from?"

2. "Do you think that matter is cycling in the EcoSphere? How does that happen?"

3. "Do you think that energy is cycling in the EcoSphere? How does that happen?"

4. "Do you think the EcoSphere has energy exchange with the outside environment? Why?" [If the answer is yes] "What energy goes into the EcoSphere? What energy comes out?"

5. "If I put the EcoSphere in a dark room for one week, what do you think will happen? Why?" 


\section{Vocabulary and Plant Structure Questions}

Purpose of the questions: Students often struggle to talk about the way that organisms are organized into different systems at different scales, including cells, molecules and atoms. In this question you find out how well a student can "dig in" to a leaf down through the hierarchy of scales, and how they understand the processes of growth and gas exchange at different scales. During growth, leaf cells "make themselves" from water, minerals, and $\mathrm{CO}_{2}$. During gas exchange in the leaf, the carbon atom from $\mathrm{CO}_{2}$ gets incorporated into sugars, which then gets made into lots of different types of molecules that make up a plant.

Student Practices: Subsystems, Mass/gases

\section{Interview Script:}

Use the "Leaf" and "Close-up of a Leaf" cards.
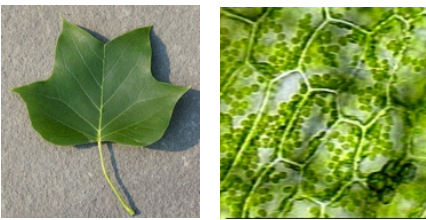

[Show student the picture of "Leaf."]

1. "Suppose that I looked at this leaf with a microscope. Can you tell me what I would see?"

2. "You said that I would see X. What are X [cells, or whatever the student says] made of?" [Continue questioning to a smaller level e.g. "what are cells made of?" until student can go no smaller.]

3. "How is the wood of the twig like the leaf? How is it different?"

[Show student the picture of a "Close-up of a leaf."]

1. "Can you tell me what you see here in this picture of a leaf?" [Point out cells if the student has not.]

2. "What do the leaf cells do as the leaf grows?"

3. "Do you think that anything is going into or out of the leaf cells as the leaf grows?" [If a student says no, or has no way of talking about gas exchange, you may skip questions 4-6]

4. "What specifically is going into or out of them?"

5. "Where does X [whatever student says; carbon dioxide, oxygen, air] come from? How does it get to the cells?"

6. "Where does X [whatever student says; carbon dioxide, oxygen, air] go after it comes out of the leaf cells?"

[Ask the questions below only if (a) the student gives evidence of some familiarity with atoms and molecules and (b) the student has not answered the questions below during first part of this interview section (above).]

Molecules:

1. "What kind of molecules do you think are in leaves?"

2. "Where are they in the leaf?"

3. "What do you think they do?

4. "Is there anything in the leaf that is not made out of molecules?"

[If the student talked about oxygen and carbon dioxide. Ask:]

5. "You said that the tree breathes in carbon dioxide and breathes out oxygen. What atoms does carbon dioxide contain?"

6. "What atoms does oxygen contain?"

7. "You said that carbon dioxide has a carbon atom, but oxygen does not have it. So, when the leaf breathes in carbon dioxide and breathes out oxygen, where does the carbon atom of $\mathrm{CO}_{2} \mathrm{go}_{\mathrm{g}}$ ?"

Atoms:

1. What kind of atoms are in the leaf?

2. "Do you think the tree contains carbon atoms?"

3. [If yes] "Where are the carbon atoms in the leaf?"

4. "Where do the carbon atoms come from?" 


\section{APPENDIX B}

\section{Scoring rubrics}

Item: FATLOSS

Fat is mostly made of molecules such as stearic acid: $\mathrm{C}_{18} \mathrm{H}_{36} \mathrm{O}_{2}$. Decide and circle whether each of the following statements is true or false about what happens to the atoms in a man's fat when he exercises and loses weight.

True False Some of the atoms in the man's fat are incorporated into CARBON DIOXIDE in the air.

True False Some of the atoms in the man's fat are converted into ENERGY that he uses when he exercises.

True False Some of the atoms in the man's fat are BURNED UP AND DISAPPEAR.

True False Some of the atoms in the man's fat are converted into HEAT.

True False Some of the atoms in the man's fat are incorporated into WATER VAPOR in the air.

Explain the pattern in your answers. What happens to the atoms in the fat of a person who loses weight?

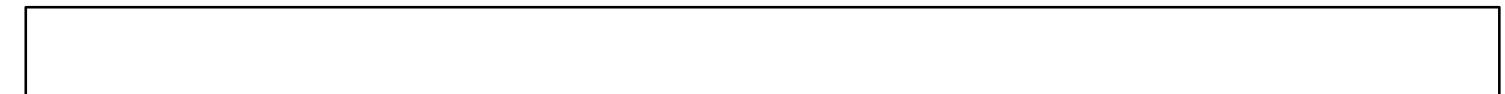

Scoring for False/True part

\begin{tabular}{lll}
\hline False or True Part & Answer & Score \\
\hline FATLOSS.CO2 & True (Correct Answer) & 1 \\
\cline { 2 - 3 } & False & 0 \\
\hline FATLOSS.EN & True & 0 \\
\cline { 2 - 3 } FATLOSS.DIS & False (Correct Answer) & 1 \\
\hline FATLOSS.HEAT & True & 0 \\
\hline FATLOSS.WATER & False (Correct Answer) & 1 \\
\hline Frue & False (Correct Answer) & 0 \\
\hline
\end{tabular}




\section{Scoring for constructed response part}

\begin{tabular}{|c|c|c|}
\hline $\begin{array}{l}\text { Constructed } \\
\text { Response Part }\end{array}$ & Score & Indicators \\
\hline \multirow[t]{15}{*}{ FATLOSS.EX } & 4 (Level 4) & $\begin{array}{l}\text { 1. Traces atoms from fat molecules to } \mathrm{CO} 2 \text { and water vapor (although mention of } \\
\text { water vapor not necessary). }\end{array}$ \\
\hline & & $\begin{array}{l}\text { 2. Traces atoms from fat molecules to other molecules AND chooses True for some } \\
\text { atoms incorporated into } \mathrm{CO} 2 \text {. }\end{array}$ \\
\hline & 3 (Level 3) & $\begin{array}{l}\text { 1. States that fat is converted into heat or energy (M/E conversion); may mention } \\
\text { exercise as the process through which this happens. }\end{array}$ \\
\hline & & $\begin{array}{l}\text { 2. States that fat is converted into sweat or other molecules/substances without } \\
\text { addressing } \mathrm{CO} 2 \text { as an accompanying byproduct. }\end{array}$ \\
\hline & & 3. States one of the laws of conservation of energy OR conservation of matter. \\
\hline & 2 (Level 2) & $\begin{array}{l}\text { 1. States that the atoms "burn up", are used up, or converted with no other } \\
\text { information. }\end{array}$ \\
\hline & & 2. States that atoms/fat completely disappear OR that fat leaves the body. \\
\hline & & 3. States that the atoms shrink/get larger. \\
\hline & & 4. Just includes everything from the prompt in a list form without an explanation. \\
\hline & & 5. ONLY explanation is that does NOT become $\mathrm{CO}_{2}$ or $\mathrm{H}_{2} \mathrm{O}$. \\
\hline & & $\begin{array}{l}\text { 6. Speaks in general terms of the processes associated with weight loss (e.g., } \\
\text { exercising, sweating) without recognizing the molecular underpinnings of these } \\
\text { processes. }\end{array}$ \\
\hline & & $\begin{array}{l}\text { 7. Does not correctly describe a physiological process i.e. fat turns to muscle without } \\
\text { any of the L3 or L4 indicators. }\end{array}$ \\
\hline & $\overline{0}$ & Unintelligible, nonsense, not related to question \\
\hline & 7 & $\begin{array}{l}\text { I don't know, I guessed, ? OR provided multiple choice with I don't know, I guessed, } \\
\text { ? or similar }\end{array}$ \\
\hline & 8 & Choice with no explanation \\
\hline
\end{tabular}




\section{APPENDIX C}

The Percentage of the Chinese Students at Each Learning Progression Level for Each Item

\begin{tabular}{|c|c|c|c|c|c|c|}
\hline \multirow{2}{*}{$\begin{array}{l}\text { Phenomenon } \\
\text { (Carbon-transforming } \\
\text { process) }\end{array}$} & \multirow[t]{2}{*}{ Item } & \multirow[t]{2}{*}{ Grade } & \multicolumn{4}{|c|}{$\begin{array}{c}\text { The Percentage of the Chinese Students at Each } \\
\text { Learning Progression Level }\end{array}$} \\
\hline & & & Others & Level 2 & Level 3 & Level 4 \\
\hline \multirow{9}{*}{$\begin{array}{l}\text { Burning } \\
\text { (Combustion) }\end{array}$} & \multirow{3}{*}{ BRNMATCHMAT } & 7 & $43.48 \%$ & $26.09 \%$ & $30.43 \%$ & 0 \\
\hline & & 8 & $33.33 \%$ & $24.44 \%$ & $42.22 \%$ & 0 \\
\hline & & 9 & $23.81 \%$ & $28.57 \%$ & $45.24 \%$ & $2.38 \%$ \\
\hline & \multirow{3}{*}{ BRNMATCHEN } & 7 & $30.43 \%$ & $69.57 \%$ & 0 & 0 \\
\hline & & 8 & $26.67 \%$ & $60.00 \%$ & $11.11 \%$ & $2.22 \%$ \\
\hline & & 9 & $11.90 \%$ & $47.62 \%$ & $33.33 \%$ & $7.14 \%$ \\
\hline & \multirow{3}{*}{ OCTAMOLE } & 7 & $36.54 \%$ & $40.38 \%$ & $23.08 \%$ & 0 \\
\hline & & 8 & $27.47 \%$ & $21.98 \%$ & $47.25 \%$ & $3.30 \%$ \\
\hline & & 9 & $7.32 \%$ & $6.10 \%$ & $52.44 \%$ & $34.15 \%$ \\
\hline \multirow{9}{*}{$\begin{array}{l}\text { Animal growth \& } \\
\text { movement } \\
\text { (Cellular respiration, } \\
\text { digestion and } \\
\text { biosynthesis) }\end{array}$} & \multirow{3}{*}{ BODYHEAT2 } & 7 & $16.67 \%$ & $50.00 \%$ & $33.33 \%$ & 0 \\
\hline & & 8 & $19.57 \%$ & $43.48 \%$ & $34.78 \%$ & $2.17 \%$ \\
\hline & & 9 & $7.50 \%$ & $42.50 \%$ & $42.50 \%$ & $7.50 \%$ \\
\hline & \multirow{3}{*}{ GIRLGROWPARTS } & 7 & $8.33 \%$ & $70.83 \%$ & $20.83 \%$ & 0 \\
\hline & & 8 & $21.74 \%$ & $56.52 \%$ & $21.74 \%$ & 0 \\
\hline & & 9 & $10.00 \%$ & $50.00 \%$ & $35.00 \%$ & $5.00 \%$ \\
\hline & \multirow{3}{*}{ FATLOSS } & 7 & $27.66 \%$ & $42.55 \%$ & $29.79 \%$ & 0 \\
\hline & & 8 & $26.37 \%$ & $35.16 \%$ & $35.16 \%$ & $4.40 \%$ \\
\hline & & 9 & $13.41 \%$ & $23.17 \%$ & $32.93 \%$ & $30.49 \%$ \\
\hline \multirow{9}{*}{$\begin{array}{l}\text { Plant growth \& movement } \\
\text { (Photosynthesis (and } \\
\text { biosynthesis), cellular } \\
\text { respiration) }\end{array}$} & \multirow{3}{*}{ OAKTREEPARTS } & 7 & $30.19 \%$ & $32.08 \%$ & $37.74 \%$ & 0 \\
\hline & & 8 & $20.65 \%$ & $26.09 \%$ & $52.17 \%$ & $1.09 \%$ \\
\hline & & 9 & $10.98 \%$ & $40.24 \%$ & $40.24 \%$ & $8.54 \%$ \\
\hline & \multirow{3}{*}{ ENERGRASS } & 7 & $36.54 \%$ & $53.85 \%$ & $5.77 \%$ & $3.85 \%$ \\
\hline & & 8 & $32.97 \%$ & $26.37 \%$ & $34.07 \%$ & $6.59 \%$ \\
\hline & & 9 & $25.00 \%$ & $50.00 \%$ & $17.86 \%$ & $7.14 \%$ \\
\hline & \multirow{3}{*}{ PLANTROOTS } & 7 & $62.07 \%$ & $24.14 \%$ & $10.34 \%$ & $3.45 \%$ \\
\hline & & 8 & $53.33 \%$ & $28.89 \%$ & $15.55 \%$ & $2.22 \%$ \\
\hline & & 9 & $26.19 \%$ & $26.19 \%$ & $45.24 \%$ & $2.38 \%$ \\
\hline \multirow{9}{*}{$\begin{array}{l}\text { Decay } \\
\text { Cellular respiration (and } \\
\text { digestion) }\end{array}$} & \multirow{3}{*}{ COMPOSTB } & 7 & $34.48 \%$ & $41.38 \%$ & $24.14 \%$ & 0 \\
\hline & & 8 & $32.61 \%$ & $34.78 \%$ & $23.91 \%$ & $8.70 \%$ \\
\hline & & 9 & $14.29 \%$ & $54.76 \%$ & $28.57 \%$ & $2.38 \%$ \\
\hline & \multirow{3}{*}{ BREADMOLD } & 7 & $58.62 \%$ & $34.48 \%$ & $6.90 \%$ & 0 \\
\hline & & 8 & $47.83 \%$ & $21.74 \%$ & $28.26 \%$ & $2.17 \%$ \\
\hline & & 9 & $42.86 \%$ & $26.19 \%$ & $26.19 \%$ & $4.76 \%$ \\
\hline & \multirow{3}{*}{ POTATO } & 7 & $50.00 \%$ & $36.54 \%$ & $13.46 \%$ & 0 \\
\hline & & 8 & $42.86 \%$ & $30.77 \%$ & $26.37 \%$ & 0 \\
\hline & & 9 & $23.81 \%$ & $23.81 \%$ & $44.05 \%$ & $8.33 \%$ \\
\hline
\end{tabular}

\section{http://www.ejmste.com}

